\title{
Perceptions and Instructional Practices used by West Virginian Secondary Agricultural Teachers in Meat Science Education
}

Kindra D. Carr

kwcarr@mix.wvu.edu

Follow this and additional works at: https://researchrepository.wvu.edu/etd

Part of the Educational Methods Commons, Science and Mathematics Education Commons, Secondary Education Commons, and the Vocational Education Commons

\section{Recommended Citation}

Carr, Kindra D., "Perceptions and Instructional Practices used by West Virginian Secondary Agricultural Teachers in Meat Science Education" (2021). Graduate Theses, Dissertations, and Problem Reports. 8009. https://researchrepository.wvu.edu/etd/8009

This Thesis is protected by copyright and/or related rights. It has been brought to you by the The Research Repository @ WVU with permission from the rights-holder(s). You are free to use this Thesis in any way that is permitted by the copyright and related rights legislation that applies to your use. For other uses you must obtain permission from the rights-holder(s) directly, unless additional rights are indicated by a Creative Commons license in the record and/ or on the work itself. This Thesis has been accepted for inclusion in WVU Graduate Theses, Dissertations, and Problem Reports collection by an authorized administrator of The Research Repository @ WVU. For more information, please contact researchrepository@mail.wvu.edu. 
Perceptions and Instructional Practices used by West Virginian Secondary Agricultural Teachers in Meat Science Education

Kindra D. Carr

Follow this and additional works at: https://researchrepository.wvu.edu/etd

Part of the Educational Methods Commons, Science and Mathematics Education Commons, Secondary Education Commons, and the Vocational Education Commons 
Perceptions and Instructional Practices used by West Virginian Secondary Agricultural Teachers in Meat Science Education

\title{
Kindra Dawn Carr
}

Thesis submitted to the Davis College of Agriculture, Natural Resources and Design at West Virginia University In partial fulfillment of the requirements for the degree of Master of Science in Agricultural and Extension Education

Jessica M. Blythe, Ph.D., Chair Rachel E. Hendrix, Ph.D. Brett P. Kenney, Ph.D.

School of Design and Community Development

\author{
Morgantown, West Virginia
}

2021

Keywords: agriculture, agricultural education, meat science, self-efficacy, STEM integration, outcome expectancy

Copyright 2021 Kindra Dawn Carr 


\begin{abstract}
Perceptions and Instructional Practices used by West Virginian Secondary Agricultural Teachers in Meat Science Education
\end{abstract}

\title{
Kindra D. Carr
}

\begin{abstract}
A focus on classroom integration of science, technology, engineering, and math (STEM) concepts has resulted in secondary teachers broadening the scope and delivery of STEM principles in their classes. Because agriculture classes allow students to convert abstract ideas into concrete ideas, they provide a useful setting to teach STEM concepts. Using secondary agricultural classes to teach science is effective and has contributed to higher standardized science test scores, as opposed to a science class alone. West Virginia is known for meat processing facilities and meat technology learning activities in its public schools. However, little is known about how the content is delivered or if secondary agricultural teachers are using meat science as a context to introduce STEM components into school-based agricultural education (SBAE) programs. This study found approximately two-thirds of the West Virginia SBAE teachers educate students about meat science, even though only slightly over half have access to a meat science laboratory. In addition, this study found that the majority of West Virginia SBAE teachers who teach meat science have already integrated STEM components into their curricula.
\end{abstract}




\section{ACKNOWLEDGEMENTS}

I would first like to thank my committee: Dr. Blythe, Dr. Hendrix, and Dr. Kenney. Without your feedback and support I would have never been able to complete this coveted master's degree! Dr. Blythe, thank you for helping me find the focus of my research. I greatly appreciate your organization and planning skills, which helped keep me on track with a realistic goal. Dr. Hendrix, thank you so much for taking the time to help with Qualtrics, sorting data, and answering my continuous line of questions! Dr. Kenney, thank you for reminding me that sometimes it is okay to stop and smell the roses, or just go turkey hunting. I have always admired your expertise in meat science. Thank you for always encouraging me to become a better writer.

To the four grad students who shared that super tiny office: I thank you for always keeping me in line and allowing me to brainstorm ideas with you. Honestly, I hate that I complained about all of the chatter that came from that little office in the beginning. I despise that we had to distance ourselves and could not return in person. I am honored to call each of you a graduate student in my cohort!

To my brothers Spencer and Brandal: I know college was never your cup of tea! Let's be honest, the whole school thing wasn't either. However, you always supported me in my educational endeavors. You were there for me when I needed help moving my belongings into my apartment, and then back out of my apartment when COVID-19 attacked. Thank you for supporting me, making me laugh, and always having my back!

Daniel, you may not know this, but you were my biggest motivation to complete this manuscript while also earning a 4.0 GPA. Thank you for constantly reminding me that I can do this and pushing me to work hard to the best of my abilities. Thank you for letting me vent to you, no matter how minor my complaint. Also, thank you for all the Chinese food deliveries you called in for me. I am so thankful to have you in my life. I love you!

Mom and Dad, where do I start? My entire life, all I wanted to do was to make you proud. I know WVU may not have been your dream for my future, but being an Agricultural Educator was mine. Thank you for standing by my side, supporting me, and just being there for me when I needed advice! Most importantly, I want to thank you for raising me to know and love Jesus Christ, which has built the foundation for my life. Although nobody is perfect, I cannot think of a better example to look up to than each of you. 


\section{TABLE OF CONTENTS}

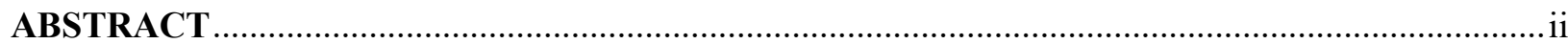

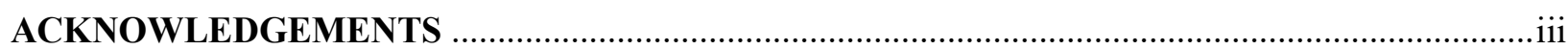

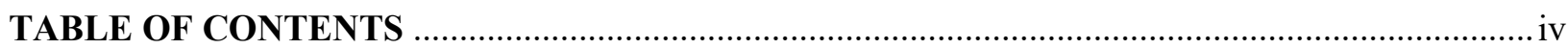

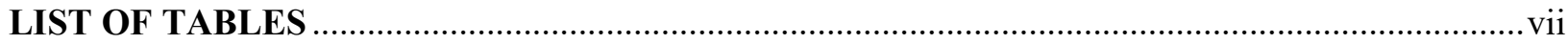

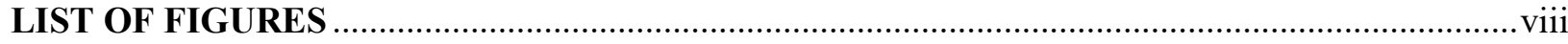

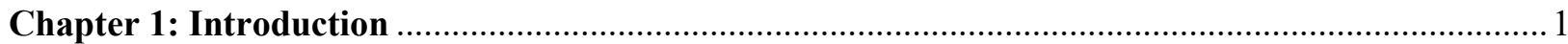

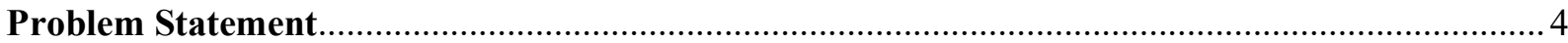

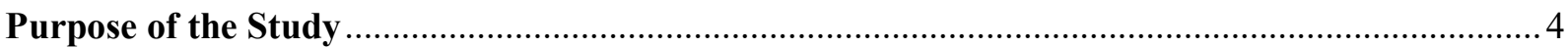

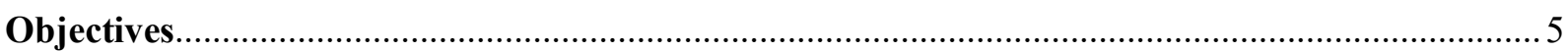

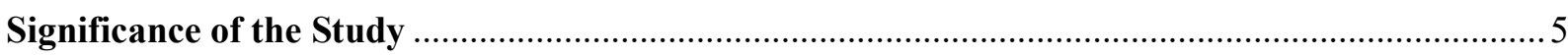

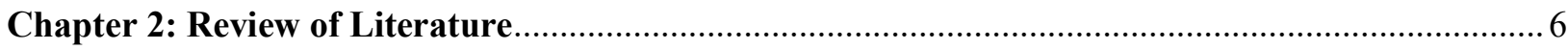

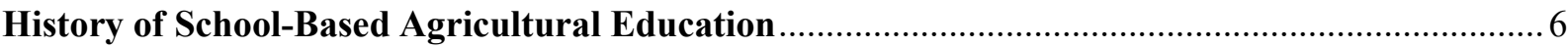

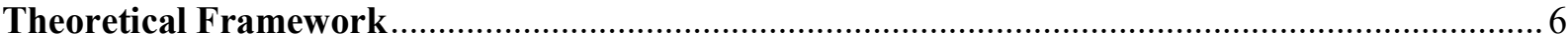

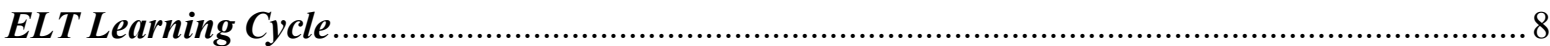

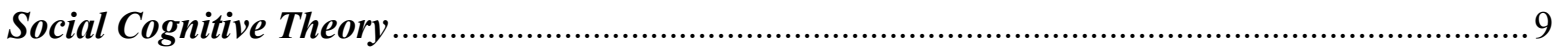

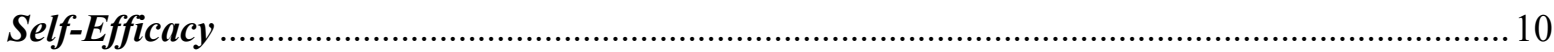

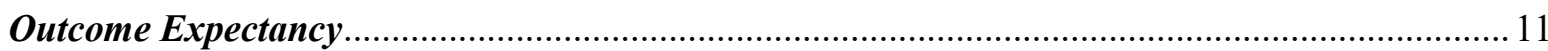

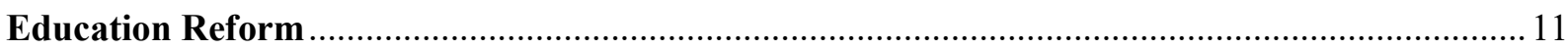

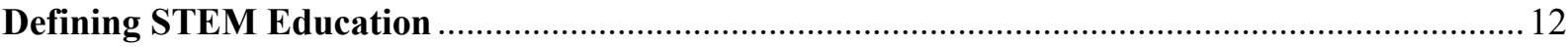

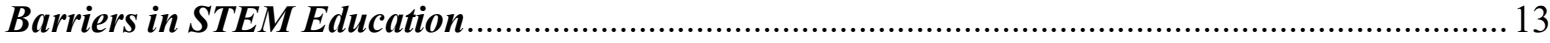

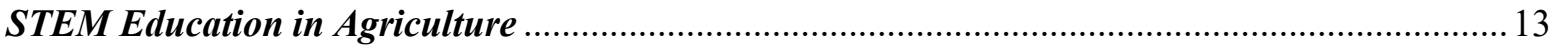

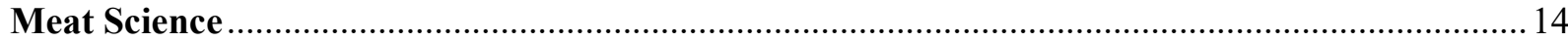

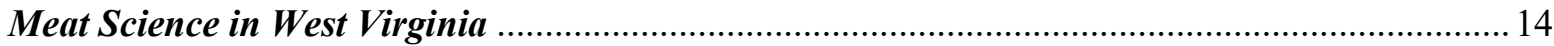

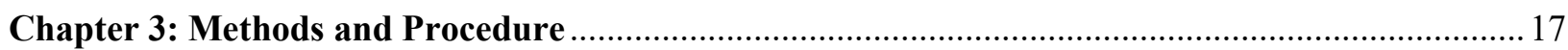

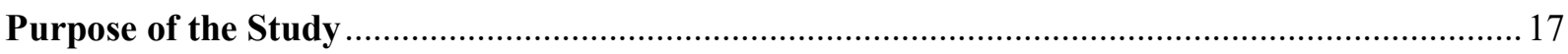

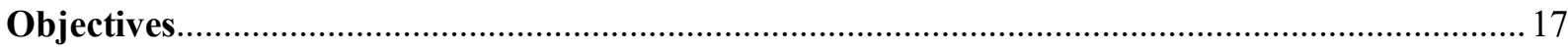

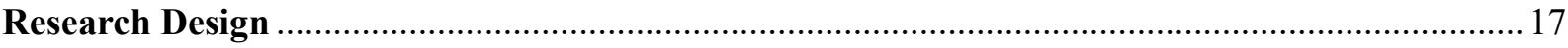

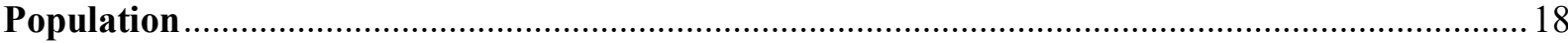

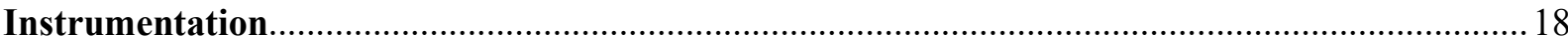




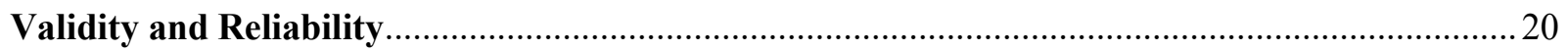

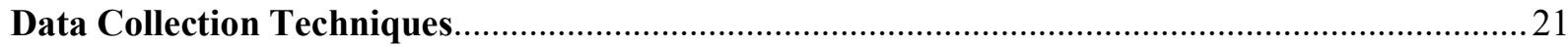

Use of Findings

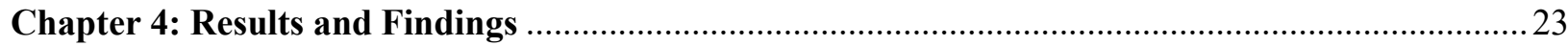

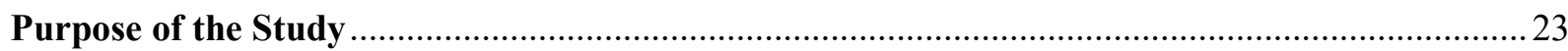

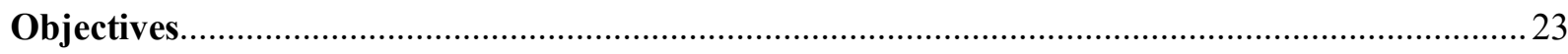

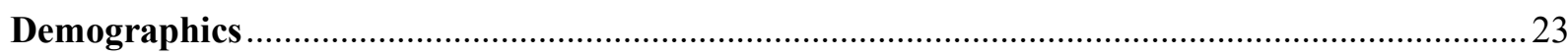

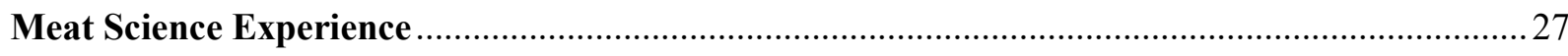

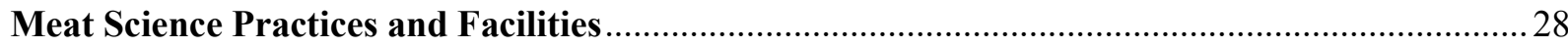

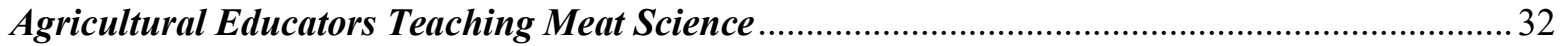

Agricultural Educators who do Not Formally Teach Meat Science ............................................. 39

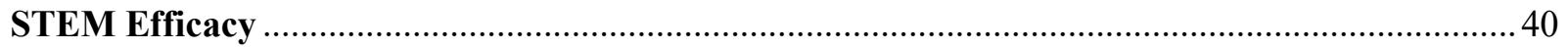

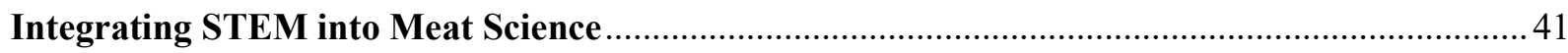

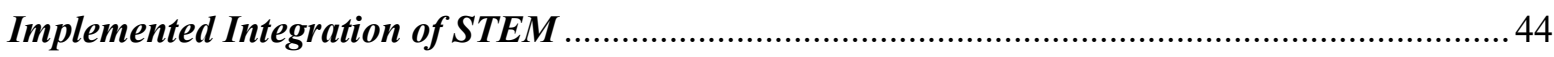

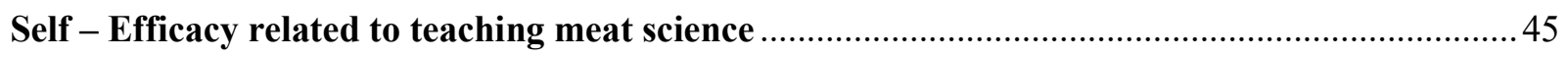

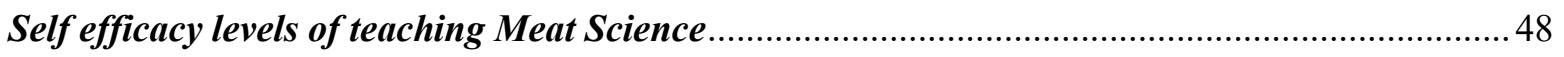

Self-Efficacy in Outcome Expectancy in Meat Science ...............................................................50

Barriers to Integrating Meat Science Curriculum ...................................................................... 53

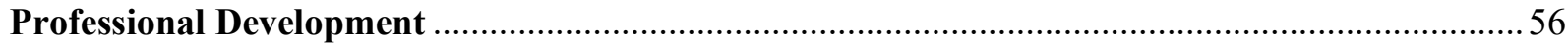

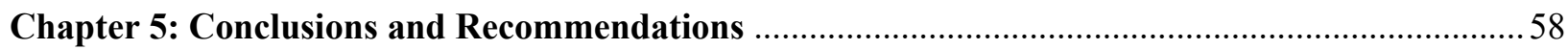

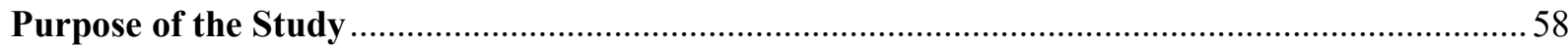

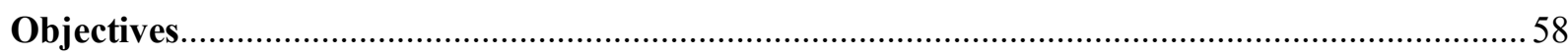

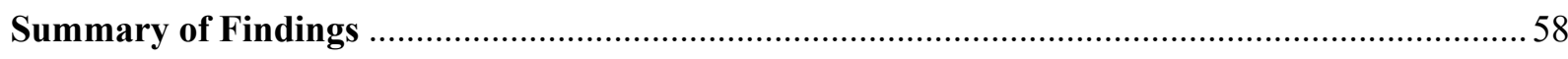

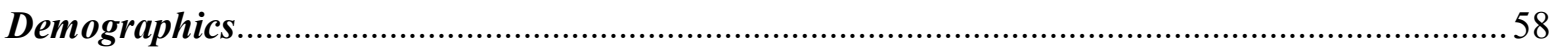

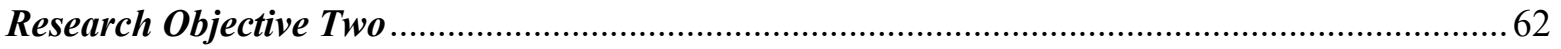

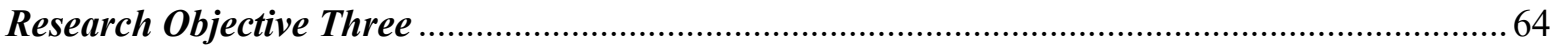

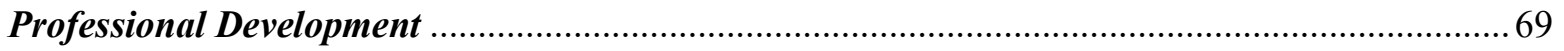

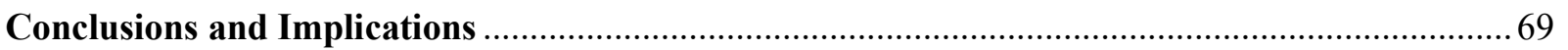

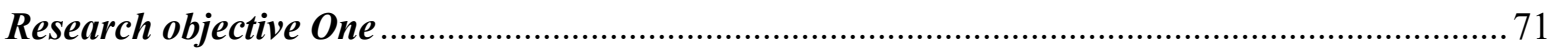

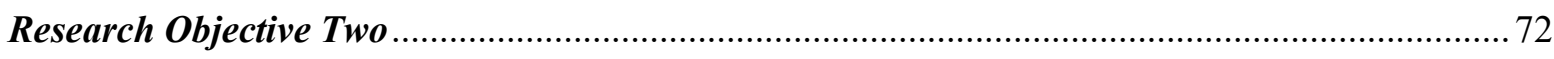

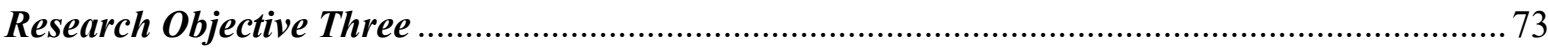

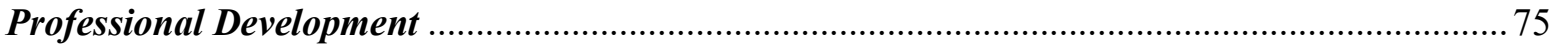

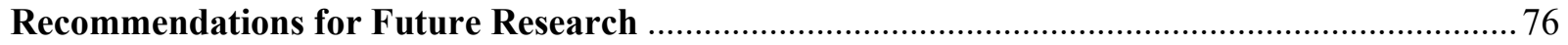




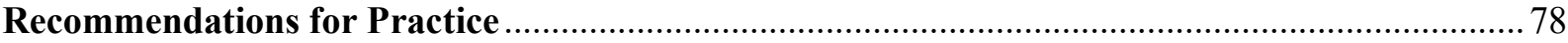

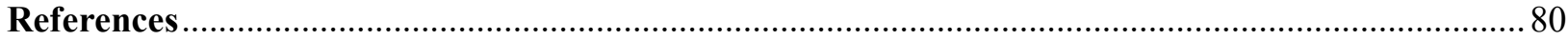

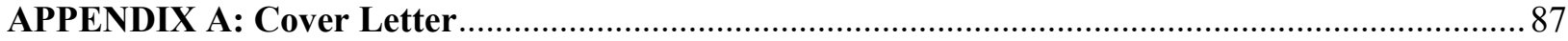

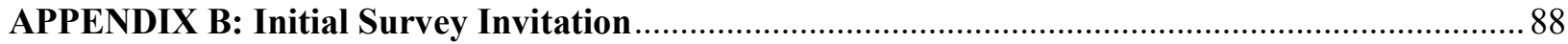

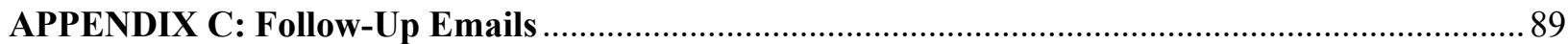

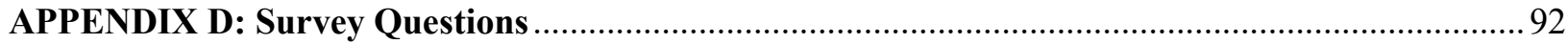




\section{LIST OF TABLES}

$\begin{array}{lll}\text { Table 1. Gender } & 24\end{array}$

Table 2. Agricultural Educators' Age and Years of Teaching Experience $\quad 24$

Table 3. Area of School Community 25

Table 4. Grade Levels Taught 26

Table 5. Meat Science Training Experience $\quad 27$

$\begin{array}{lll}\text { Table 6. } & \text { Meat Lab Access } & 28\end{array}$

Table 7. Equipment in Meat Lab 29

Table 8. Types of Meat Science Practices $\quad 31$

Table 9. How is Meat Science taught? 32

Table 10. Teaching Methods $\quad 33$

Table 11. Depth of Topics $\quad 35$

Table 12. Depth of Meat Science Species $\quad 37$

Table 13. Average Number of Days teaching Meat Science per Month 38

Table 14. Reasons for Not Teaching Meat Science 39

Table 15. Confidence in Ability to Teach STEM components 40

Table 16. Perceptions of Integrating STEM Components into Meat Science $\quad 42$

Table 17. Integration of STEM 44

Table 18. Confidence in Knowledge of Meat Science Topics $\quad 46$

Table 19. Ranking Confidence of Species Taught $\quad 47$

Table 20. Self-Efficacy in teaching Meat Science $\quad 49$

Table 21. Self-Efficacy Levels of Outcomes Expectancy in Teaching Meat Science 51

Table 22. Barriers of Integrating Meat Science into Curriculum 54

Table 23. Professional Development 56 


\section{LIST OF FIGURES}

Figure 1. School-Based Agricultural Education Three Circle Model $\quad$ S

Figure 2. Kolb's Experiential Learning Theory $\quad 9$

Figure 3. Bandura's Social Cognitive Theory 10 


\section{Chapter 1: Introduction}

Although many things have changed in the evolution of the school-based agricultural experience (SBAE) program, one thing has stayed the same: experiential learning (Barrick \& Hughes, 1993; Cheek et al., 1994; Knobloch, 2003). Roberts (2011) defines experiential learning as "the cyclical process by which learners transform their experiences into knowledge" (p. 4). SBAE utilizes a three-circle model to provide opportunities where youth can develop leadership, personal growth, and career success (Barrick \& Hughes, 1993), and experiential learning is evident throughout all parts of the model (Cheek et al., 1994).

\section{Figure 1}

School-Based Agricultural Education Three Circle Model

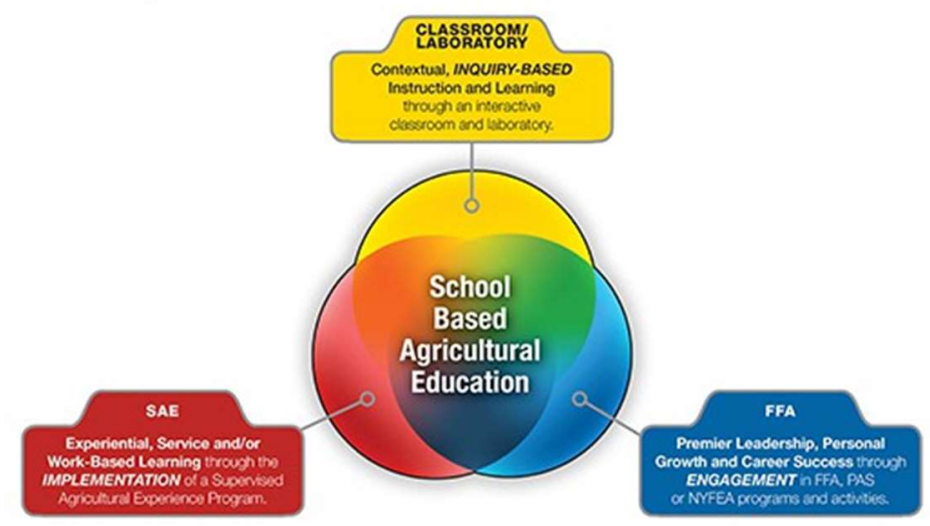

(National FFA Organization, 2021)

As shown in Figure 1, this model starts in the classroom/laboratory, where students engage in basic instructions of agricultural theory before progressing to the laboratory, where their knowledge is put to use and integrated with problem-solving strategies (Cheek et al., 1994). In laboratories, students engage in student-led learning through experiential learning theory activities. They can then apply their knowledge to their Supervised Agricultural Experience (SAE) (Cheek et al., 1994), which is another component of the three-circle model. 
An SAE is a student-led experience program (Barrick et al., 1993), in which students apply classroom knowledge to real-world situations involving the agriculture industry. Students keep records of their SAEs and are often expected to work on this program outside of the classroom (Croom, 2008). A plan and contract are made between the student, advisor, parent, and employer to ensure the student is gaining valuable learning experiences (Croom, 2008). The final circle of the model represents the National FFA Organization. The National FFA Organization is a student-led, intracurricular organization that assists students in career exploration, leadership development, and communication skills (National FFA Organization, 2020).

Not only does SBAE provide students with a platform for experiential learning, this education also gives context for integration of other vital subjects. An agriculturalist must know many different trades and have knowledge and skills to support the critical thinking and problem solving needed in the agricultural industry. The versatility needed to address multiple tasks must be taught in the agricultural education classroom. An agriculturist may need to be a mechanic one day, and a soil scientist the next. STEM education incorporates components of science, technology, engineering, and mathematics (Bybee, 2010). Such diverse challenges can be met through the integration of science, technology, engineering, and mathematics (STEM) education (Bybee, 2010). SBAE laboratories, including meat science laboratories, agricultural mechanics, greenhouses, animal production labs, and veterinary science facilities, provide a valuable opportunity to integrate STEM education. Agriculture classes provide excellent context to teach STEM because these classes allow students to convert abstract ideas into concrete ideas in real-world situations (Melodia \& Small, 2002; Smith \& Rayfield, 2017). Students enrolled in school-based agricultural education programs had significantly higher math and science scores on standardized tests when compared to students enrolled in only math and science classes (Smith et al., 2015; Ricketts et al., 2006). This study will examine teachers' use of the meat 
science curriculum and laboratory to integrate STEM education.

The SBAE programs in West Virginia are known for their expertise in meat science (Porter, 2014). In a recent study, meat labs account for only $4 \%$ of laboratories used in agricultural education programs across the nation (Shoulders \& Myers, 2011). In West Virginia, however, $84.62 \%$ of the high school agriculture programs have access to a fully functional meat processing laboratory (Porter, 2014). These facilities have the ability to preserve, process, and store meats (Porter, 2014). Meat labs in West Virginia normally possess a cooler, freezer, cutting room, smoker, band saw, grinders, vacuum sealers, and cutting tables (Porter, 2014).

One of the primary reasons meat processing labs are so important to the SBAE programs throughout West Virginia is student participation in the state and local Ham, Bacon, and Egg (HBE) shows and sales. These unique shows date back to 1941 (Moore, 2020); at this time, the country was coming out of the Great Depression and food security was at an all-time low (Moore, 2020). However, in West Virginia, SBAE programs assisted in educating the community about preserving ham and bacon products through salt curing, and in the production of eggs (Moore, 2020). Similar to the corn club model, which used youth education to spread much-needed innovation to the broader community (Uricchio, C., et. al., 2013). This system continued; for the past 80 years, agricultural education teachers have worked with the West Virginia FFA Association to promote the state HBE show and sale, educate the community about egg production, and teach dry curing to preserve ham and bacons (Moore, 2020).

Students participating in the HBE show implement uniquely practical skills through their STEM learning. At the HBE show, students from across the state present their ham and bacon products which they have worked diligently to prepare (Hess, 2017). The students start by purchasing a piglet during the summer months before spending the next 6-8 months raising the pig to the proper market weight (Hess, 2017). Hogs are then butchered in a state-regulated 
facility and transported to the SBAE program's meat lab to be further processed by the students (Knollinger, 2019). Students cure, trim, and smoke the hams and bacons. Students who raise chickens choose their most uniform and freshest eggs to compete in the show (The Market Bulletin, 2019). Throughout this process, students learn proper nutrition, curing measurements/weight ratios, curing time, trimming techniques, and how to properly smoke meat (Hess, 2017).

\section{Problem Statement}

A focus on classroom integration of science, technology, engineering, and math (STEM) concepts has resulted in secondary teachers broadening the scope and delivery of STEM principles in their classes. Because agriculture classes allow students to convert abstract ideas into concrete ideas, they provide a useful setting to teach STEM concepts (Smith \& Rayfield, 2017). Using secondary agricultural classes to teach science is effective and has contributed to higher standardized science test scores, as opposed to an individual science class alone (Smith et al. 2015; Ricketts et al., 2006). West Virginia is known for meat processing facilities and meat technology learning activities in its public schools. However, little is known about how the content is delivered or if secondary agricultural teachers are using meat science as a context to introduce STEM components into school-based agricultural education (SBAE) programs.

\section{Purpose of the Study}

The purpose of this study was to describe current practices being used by West Virginia's secondary agricultural teachers regarding instruction in the meat laboratory. This includes current methods, choice and depth of topics, seasonal preference for teaching meat science, and teachers' levels of integration of STEM components in their SBAE programs. This study also describes self-efficacy levels related to delivering meat science content, and STEM integration of 
the current West Virginia SBAE teachers.

\section{Objectives}

- Describe current practices related to delivering secondary meat science education in West Virginia.

- Determine teachers' use of meat science as a context to introduce STEM components into their school-based agricultural education program.

- Describe self-efficacy levels related to teaching meat science of current West Virginia school-based agricultural education teachers.

\section{Significance of the Study}

This study is important to current and future West Virginia secondary agricultural educators and students, all of whom benefit from training in meat science and an understanding of broader STEM disciplines. Before professional development can be implemented to emphasize more sophisticated STEM concepts in the meat science laboratory, we must first understand how meat science is currently taught. This research will enable an assessment of weaknesses in teaching meat science across the state, and lead to subsequent professional development opportunities for each SBAE teacher in West Virginia. Most importantly, this study is important to the development of our youth; by equipping teachers with more meaningful lessons regarding meat science, students will gain a higher level of understanding in various STEM concepts, as well as practical skills in the field of agricultural education. 


\section{Chapter 2: Review of Literature}

\section{History of School-Based Agricultural Education}

School-based agricultural education (SBAE) officially began February 23, 1917 (National FFA Organization, 2020). On this day, President Woodrow Wilson signed the SmithHughes Act, providing federal funds to incorporate vocational education into public schools (Moore, 2017). Vocational education included components of agriculture, trades, and home economics (Moore, 2017). Each of these classes provided students with the information and skills needed for life outside of high school (Moore, 2017). However, the idea of providing agricultural education to students in public schools started long before the Smith-Hughes act was passed (Moore, 2017). In fact, one year before the Smith-Hughes Act was passed, there were approximately 3,675 secondary schools that offered agricultural education to more than 73,000 students (True, 1929). Still, the Smith-Hughes Act was a turning point in the nation's prioritization of school-based agricultural education; prior to its passing, the education system in the United States focused on teaching classical subjects such as Greek and Latin, which were not practical to the majority of the public school students across the country (National FFA Organization, 2020).

\section{Theoretical Framework}

The theoretical framework that will be used to guide this study is the experiential learning theory (ELT). David Kolb (2009) defines experiential learning as a "process in which learning occurs from the combination of grasping and transforming experience" (p. 44). The roots of ELT date back to the 18th century, when John Dewey took a stand against traditional methods of teaching and learning (Kolb \& Kolb, 2009). In contrast to the rote memorization and inflexible methods of his time, Dewey espoused the belief that education should stem from the interests of 
the students and should be more applicable to their environment (Dewey, 1897). Additionally, Dewey believed a meaningful experience always preceded the occurrence of learning (Dewey, 1986). He also believed that teachers need to fill the role of a facilitator in education by helping students find and discover what interests them (Dewey, 1897). Teachers should then provide students with meaningful learning opportunities to help them expand and deepen their learning in that field (Dewey, 1897). Kolb constructed the ELT by piecing together findings from several foundational scholars including John Dewey, William James, Kurt Lewin, Jean Piaget, Lev Vygotsky, Carl Jung, Mary Parker Follett, and many others (Kolb, 2015). Kolb identified six main concepts that these founding scholars had in common within their research in regard to ELT (Kolb et al., 2009). The main priority of the learning process should be to engage students in a process that not only makes them want to learn, but in a way that intensifies what they learn. This process should be a continuous reconstruction of experience, in combination with constructive feedback towards students' achievements and failures. 2) Learning happens most efficiently when the topics are drawn from the interest and culture of the student. New learning can then be added to the previous knowledge to create a new understanding. 3) Learning occurs best when one is constantly shifting their ways of reflection, action, feeling, and thinking. Thus, learning can especially arise from conflicts, differences, and disagreements. 4) Learning is more than simply gaining knowledge; it draws from many different functions of the whole person (thinking, feeling, perceiving and behaving), and includes the strengthening of problem-solving skills, decision-making, and creativity. 5) Learning occurs when people interact with the environment around them. These interactions lead to a string of choices and decisions unique to the individual. As such, different experiences and different knowledge arise based on individual choices and contexts. 6) Knowledge is constantly being recreated from the time one is born. 


\section{ELT Learning Cycle}

The ELT learning cycle by David Kolb was first published in 1984. Since then, Kolb has updated his original view based on more recent research and findings (Kolb et al., 2009). Despite new revisions, Kolb maintains that learning is a constructive process (Kolb et al., 2009). Knowledge is not a quality that can be downloaded or memorized. Rather, it is a process drawn from life experiences. As everyone has different experiences, everyone draws from a different experience bank. Furthermore, the ELT explains that knowledge is created from grasping and transforming knowledge (Kolb, 2015). To grasp knowledge is to have a basic understanding of the concept (Kolb et al., 2001). There are 2 ways to grasp knowledge: through concrete experience or abstract conceptualization (Kolb et al., 2001). To transform knowledge is to reach the point where experience or conceptualization is converted into knowledge. According to Kolb, there are 2 ways to transform knowledge: reflective observation and active experimentation (Kolb, 2015). Learners grasp knowledge through experience, reflect on what happened, mentally conceptualize what to do better next time, and then test it.

According to Kolb et al. (2009), the ELT revolves in a continuous cycle within 4 different learning modes: experiencing, reflecting, thinking, and acting. As a result, in order for learning to occur, the instruction should include each of these 4 learning modes. As illustrated in Figure 2, the cycle starts with a concrete example, which provides the experience; later, this will result in observation and reflection. The reflections are then transformed into abstract concepts or new understandings. In processing those new understandings, learners think of ways to improve the experience to create a superior outcome. Lastly, the abstract concepts are actively tested to create new experiences, which are subsequently tested as the cycle begins again.

\section{Figure 2}




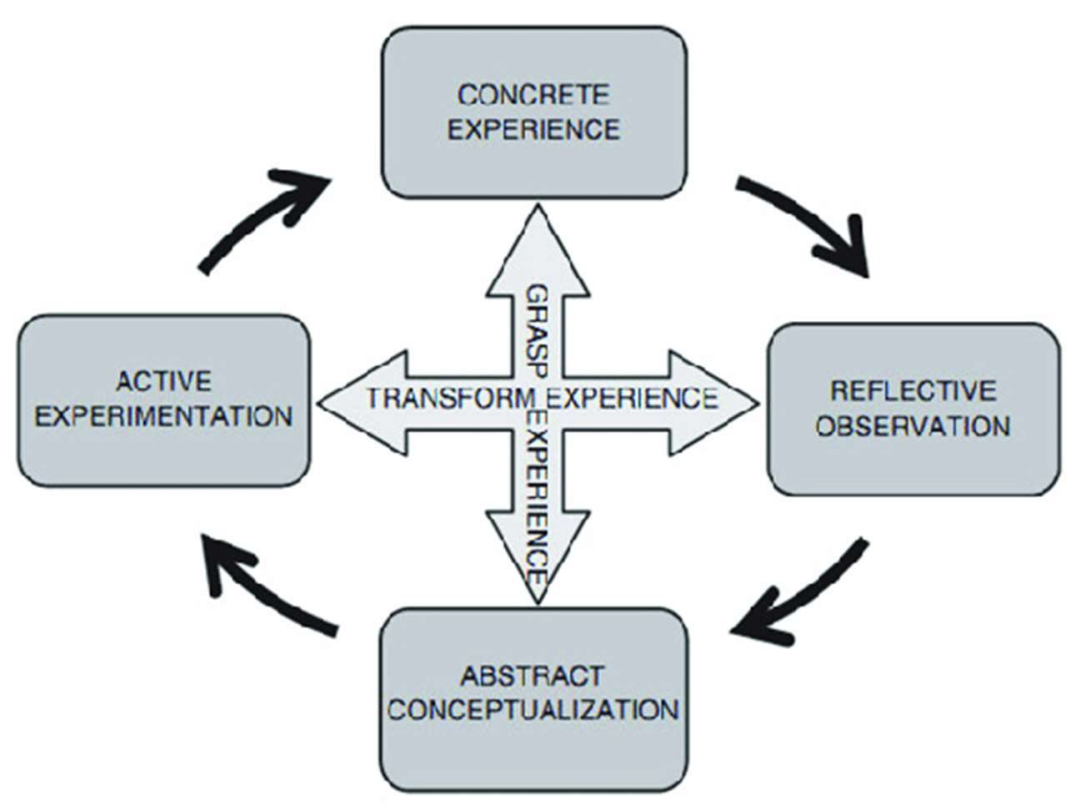

(Kolb, et. al., 2009)

\section{Social Cognitive Theory}

The choice of topics and how they are delivered in the agricultural classroom is largely left up to the discretion of the teacher. Being able to better understand why and how teachers make decisions can assist in improving STEM integration, and the delivery of meat science curriculum. The decisions to incorporate certain areas of focus such as STEM can be explained through the Social Cognitive Theory. Similar to David Kolb, Bandura (1986) states that the learning and development process draws from a collection of past behavior, social environments, and personal characteristics. Each of these variables interact with one another and are related, which is also known as triadic reciprocal causation (Bandura, 1986).

\section{Figure 3}

Bandura's Social Cognitive Theory 


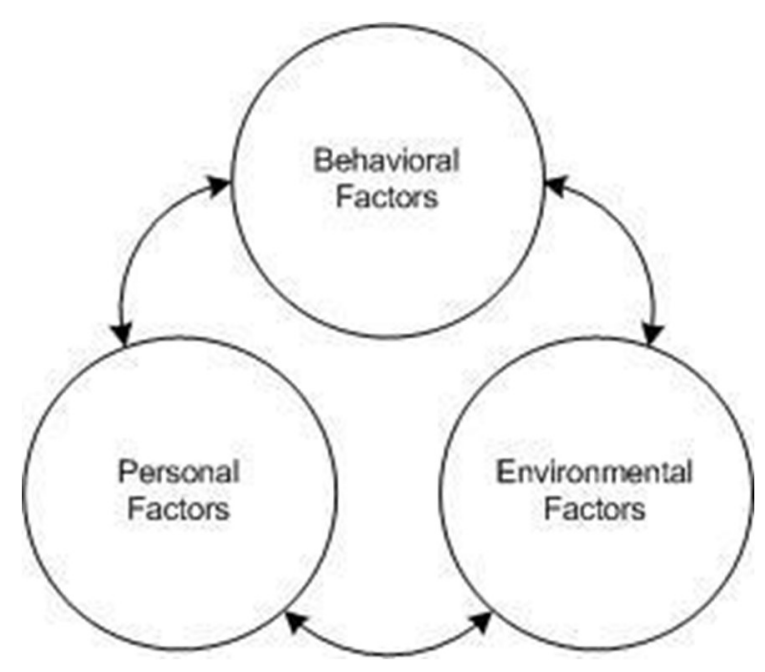

(Brockey, R., 2021)

Personal factors, or the intrinsic characteristics of the person such as metacognitive knowledge, personalities, self-efficacy, personal goals, and self-confidence, are the first variable in Bandura's social cognitive theory (Dalton State, 2021). This is followed by environmental factors, or the settings that influence one's ability to successfully complete a behavior (Dalton State, 2021). This includes not only the physical environment, such as a classroom, but also things that are going on in the environment; in a classroom example, this would include factors such as teaching methods, the influence of others, and learning strategies. The final factor is behavioral, or the way one acts in certain situations, reflects on that behavior, and works to improve the outcome of the next related situation (Dalton State, 2021).

\section{Self-Efficacy}

Self-efficacy is the belief in one's self to organize and execute the course of action in order to manage the situation at hand (Bandura, 1986). Essentially, this means that self-efficacy is the amount of confidence one has in oneself to produce the desired end goal. In terms of the triadic reciprocal causation, self-efficacy is a personal characteristic, and deals with intrinsic 
factors of the individual (Bandura, 1986). The level of self-efficacy can impact the individual's dedication, persistence, motivation, goals, choices, and how they respond to a challenge (Luszczynska \& Schwarzer, 2005). People with high self-efficacy tend to be more confident, optimistic, and can recover from failures and disappointment (Dalton State, 2021). Furthermore, people with low self-efficacy tend to be less confident, which results in avoidance of challenging tasks (Dalton State, 2021). Levels of self-efficacy can come from many different sources (Bandura, 1997). This includes mastery or failure at a task, social comparison, verbal persuasion, or emotional arousal when a task seems simple due to a lack of challenges (Luszczynska \& Schwarzer, 2005).

\section{Outcome Expectancy}

Outcome expectancy is the level at which teachers expect certain behaviors to produce desirable outcomes (Riggs \& Enochs, 1989). In many cases, the teacher has no control over these behaviors; for example, students' cultures, beliefs, opinions, interests, physical needs, and psychological needs are behaviors outside of a teacher's control. Outcome expectancy is associated with teaching efficacy (Bandura, 1989). Bandura also speculated that those with both high outcome expectancy and high teaching efficacy were motivated for the task at hand. However, those who had low outcome expectancy and high efficacy would work diligently at the start, but later become frustrated and then quit.

\section{Education Reform}

Ever since the Soviet Union successfully launched Sputnik, the world's first artificial satellite to enter into outer space, there has been a push to increase science education in the United States of America (Haynes et al., 2012; Smith \& Rayfield, 2016). In 1957, the launch of Sputnik caused turmoil and fear across the American public due to the uncertainty of foreign 
cultures' ability to launch missiles and nuclear weapons onto American lands (Dunbar, 2021). This not only led to a call for inventors and scientists to develop U.S. satellites, but also to the need to improve public education and train future scientists and inventors (Dunbar, 2021). Motivated by the space race, researchers have studied more efficient and effective teaching methods and ways to facilitate learning while using the scientific method (Ricketts et al., 2006; Smith \& Rayfield, 2016). Researchers worked to incorporate more student-centered teaching methods (Hannafin \& Land, 1997), including STEM education.

\section{Defining STEM Education}

The concept of science, technology, engineering, and mathematics (STEM) education was created by the National Science Foundation in 1990 to help improve knowledge of the scientific process in the educational system, and to increase students' understanding of how the world around them works (Dugger, 2010). The overall objective of STEM education is to incorporate science, technology, engineering, and mathematical components into other disciplines within the school (Gonzalez \& Kuenzi, 2012). STEM education challenges students to think more deeply and to use problem-solving strategies to answer questions (Bybee, 2013). By integrating STEM education into public classrooms, students learn essential skills to assist in preparing for life after high school. According to Rodger Bybee (2010), these skills, known as $21^{\text {st }}$ Century Skills, include adaptability, complex communication, social skills, non-routine problem solving, self-management, and systems thinking to enable students to compete in the modern economy. According to Stone (2011), STEM education encourages a more meaningful and challenging learning environment. 


\section{Barriers in STEM Education}

The term STEM education is ambiguous and unclear in its connotation (Sanders, 2008).

When discussing STEM, many discuss only science and math rather than all 4 components (Bybee, 2013). For this reason, many refer to true STEM education as integrative STEM education, meaning that two or more components are being incorporated in the lesson or program (Sanders, 2008). In many cases, it may be difficult to include each component in every single lesson. However, the inclusion of technology and engineering in addition to science and math is vital to building problem-solving skills through instruction (Bybee, 2010). Other barriers to effective STEM education include a lack of equipment and adequate funding needed for programs and materials (Balschweid \& Thompson, 2002)

\section{STEM Education in Agriculture}

Agricultural education and other Career and Technical Education (CTE) programs have proven to be a useful and effective setting to incorporate science, technology, engineering, and mathematics concepts (Balschweid \& Thompson, 2002; Boone et al., 2006; Clark, 2013; Conroy et al., 2000; Haynes et al., 2012; Johnson, 1996; Levesque et al., 2010; Myers \& Thompson, 2009; Myers \& Washburn, 2008; Parr et al., 2006, 2009; Ricketts et al., 2006; Scales et al., 2009; Shinn et al., 2003; Swafford, 2018; Thompson \& Balschweid, 1999; Warnick et al., 2005). Agricultural education delivers concrete examples through which abstract concepts can be applied. This focus on learning by doing allows for student-centered education to occur (Clark et al., 2013; Stone, 2011). A student-centered learning environment allows the student to play a more active role in their own education, rather than in taking a passive role in a teacher centered learning environment (Hannafin \& Land, 1997). As a result, the student-centered learning environment has been proven to encourage the use of higher order skills such as problem-solving 
skills and critical thinking (Hannafin \& Land, 1997). Agriscience laboratories, including meat science laboratories, provide a student-centered learning environment allowing students to take charge of their own learning.

\section{Meat Science}

According to Meat Science and Application, meat is defined as "edible postmortem components originating from the live animal or the tissues exclusively originating from an animal carcass" (Hui et al., 2001, p. 2). Consumption of meat has been a vital element in the diet of generations before us (Hui et al., 2001). Meat provides the protein needed to make energy within the human body (Hui et al., 2001). In 1905, the University of Minnesota was the first land-grant university to establish a meat science program (Beerman, 2009). Meat science is defined as the study of the process of changing characteristics of muscle and tissue as it is transformed into meat (Aberle \& Forrest, 2001). This includes the science of production, processing, and preservation of meats (Aberle \& Forrest, 2001). Researchers have worked to better understand meat science factors such as meat safety, meat quality attributes, carcass traits, and tenderness variation, which has led to new genetic advancements with the animal science industry. (Beerman, 2009).

\section{Meat Science in West Virginia}

The agricultural programs in West Virginia are known for their expertise in meat science (Porter, 2014). In a study conducted by Shoulders and Myers (2011), it was found that meat labs account for only $4 \%$ of laboratories used in agricultural education programs across the nation; in West Virginia, however, $84.62 \%$ of school-based agricultural education programs have access to a meat lab (Porter, 2014). Porter (2014) found the average West Virginia meat lab was 2330.50 square feet, the average cooler size was 291.56 square feet, and the average freezer size was 
83.50 square feet. Meats Labs in West Virginia normally possesses a chest or stand-up freezer, a smoker, band saw, grinder, vacuum sealer, slicer, hand saw, meat tenderizers, patty makers, and other vital processing equipment (Porter, 2014).

In 2014, 74.43\% of the West Virginia school-based agricultural education programs that had access to a meat lab also had a custom or commercial license (Porter, 2014). These meat labs processed different species of carcasses, including beef, pork, sheep, goats, chickens, turkey, and venison (Porter, 2014). An average of 61.33 students used the meat labs in each school throughout West Virginia (Porter, 2014). Of the West Virginia agricultural education teachers who did not have access to a meat lab, $44 \%$ were interested in starting one, but lacked efficient funding, knowledge of meat science and time (Porter, 2014).

Although meat labs are facilities that are used to help teach meat science and processing, West Virginia also uses them to accommodate for a very well-known Supervised Agricultural Experience (SAE), the Ham, Bacon and Egg Show. The first HBE sale took place in the Daniel Boone Hotel in Charleston, West Virginia, where the Grand Champion ham sold for $\$ 204.82$ (The Market Bulletin, 2019). The Grand Champion ham at the 2021 WV State ham bacon, and egg show sold for $\$ 1100.00$ (ShoWorks Auction, 2021).

At this show, students from across the state exhibit ham and bacon products which they have worked to prepare (Hess, 2017). This process starts when the student purchases a piglet during the summer months before spending the next 6-8 months raising the pig to the proper market weight (Hess, 2017). Hogs are then butchered in a state-regulated facility and transported back to the high school's meat lab to be further processed by the students (Knollinger, 2019) Throughout this process, students learn proper animal nutrition, the curing process, trimming techniques, and how to properly smoke meat (Hess, 2017). In addition to the state Ham, Bacon 
and Egg Show there are local shows that are held at the county and regional levels all across the state (The Market Bulletin, 2019). Porter (2014) found approximately 26 students from each West Virginia school that had access to a meat lab participated in the Ham, Bacon and Egg Show at the county level. This average rose to 90 students for shows at the regional level and rose again to 150 for the state show. While participation in the Ham, Bacon and Egg Show is a West Virginia tradition, it is also popular because students can earn substantial amounts of money if their meat is purchased in the post-Show sale.

This unique show dates back to 1941. At this time, the country was coming out of the Great Depression and food security was at an all-time low (Moore, 2020). However, West Virginia school-based agricultural education programs assisted in educating their communities about successful egg production and meat preservation through salt curing (Moore, 2020). Although the program started on a local level, teachers soon worked with the West Virginia FFA Association to promote the State Ham, Bacon and Egg show and sale, which has now been a tradition for the last 80 years (Moore, 2020). 


\section{Chapter 3: Methods and Procedure}

\section{Purpose of the Study}

The purpose of this study was to describe current practices being used by West Virginia's secondary agricultural teachers regarding instruction in the meat laboratory. This includes current methods, choice and depth of topics, seasonal preference for teaching meat science, and teachers' levels of integration of STEM components in their SBAE programs. This study also describes self-efficacy levels related to delivering meat science content, and STEM integration of the current West Virginia SBAE teachers.

\section{Objectives}

- Describe current practices related to delivering secondary meat science education in West Virginia.

- Determine teachers' use of meat science as a context to introduce STEM components into their School-Based Agricultural Education Program.

- Describe self-efficacy levels related to teaching meat science of current West Virginia school-based agricultural education teachers.

\section{Research Design}

This study utilizes a descriptive survey method to determine tangibles and intangibles (Ary et al., 2014) regarding how meat science is taught in West Virginia SBAE programs. Tangibles are defined as items that can be directly assessed by observation such as age, gender, and class enrollment. Intangibles are defined as constructs that are not directly observable, but rather inferred from indirect measurable data such as opinions, attitudes, values, perspectives, and confidence. A descriptive study is used to provide basic information and demographics 
(Swatzell \& Jennings, 2007). Web-based surveys have many advantages that include cost efficiency, prompt return, and completion at the pace and security of the participant (Dillman et al., 2014). However, one of the biggest advantages of web-based surveys is the ability to reach larger populations across a wider area (Ary et al., 2014). A web-based survey was chosen to gather information about how meat science is currently taught across West Virginia. West Virginia secondary agricultural teachers throughout the state were emailed an invitation as well as a link to participate in a Qualtrics survey. Using email to reach West Virginia agriculture teachers is the most efficient means of communication because all teachers in West Virginia have access to the internet and a state-issued email address. This survey was designed to gather descriptions and data surrounding current practices used by secondary agricultural teachers to deliver meat science content to the students enrolled in their programs and to determine teachers' use of meat science as a context to introduce STEM components into their SBAE program. Furthermore, this survey was created to gather teacher descriptions of their self-efficacy levels related to their ability and confidence in knowledge of teaching meat science.

\section{Population}

The target population for this research study was comprised of West Virginia SBAE teachers during the 2020-2021 school year. For this study, a census of all available West Virginia agricultural teachers (108 teachers in $81 \mathrm{SBAE}$ programs) was asked to participate. The accessible population for this study was the teachers who could be reached by an email address $(N=110)$. Using email to reach WV agriculture teachers was the most efficient due to the fact that all teachers in WV have access to the internet and a state-issued email address.

\section{Instrumentation}

A web-based survey instrument was used for this study due to the accessibility and cost 
efficiency. This instrument was designed to measure and describe current practices used by secondary agricultural teachers to teach meat science, and the teachers' use of meat science as a context to introduce STEM components to their SBAE programs. This instrument was also created to gather teacher descriptions of their self-efficacy levels related to their ability and confidence in teaching meat science, using both Likert-type and open-ended questions.

This descriptive survey utilized skip logic to allow participants to address questions targeted to their level of experience with meat science. First, this descriptive survey asked questions related to participants' meat science practices, accessibility, equipment, confidence levels toward teaching meat science, and meat science training experience. Depending on the answer chosen for their current practices, participants were directed to another set of questions concerning their current practices. Participants who chose "I do teach meat science" were directed to questions to assess their methods, topics covered, depth of topics, their seasonal preference, and their perspectives of using meat science as a context to incorporate STEM components. Participants who chose "I do not teach meat science" were directed to questions to assess what obstacles prevent them from teaching meat science. Participants who chose "I do not teach meat science but participate in the Ham, Bacon and Egg (HBE) show" were directed to questions assessing their perspectives of using HBE activity as a learning experience. All participants were then directed to a set of questions to assess their self- efficacy levels in teaching meat science, their self-efficacy levels in expectancy outcomes of teaching meat science, and barriers to integrating meat science into their curriculum. The final question regarding meat science asked what types of professional development would help them to be more confident in teaching meat science. Participants were then directed to a demographics portion which asked questions concerning age, gender, years of teaching experience in agricultural education, the type of area their program is located, grade levels they teach, and 
what types of meat science training they had experienced.

\section{Validity and Reliability}

Validity is currently defined as "the degree to which evidence and theory support the interpretations to test scores entailed by proposed uses of tests" (Ary et al., 2014, p. 242). In the past, it was known as the degree to which an instrument measures what it claims to measure. Face validity refers to the degree an examinee believes the instrument appears to measure the construct of interest. Both face and content validity were used to determine if this instrument appeared capable of producing accurate results. To determine if this instrument appeared to be capable of producing accurate results, it was presented to a panel of 5 professors from West Virginia University: Dr. Jessica Blythe, Dr. Rachel Hendrix, Dr. Brett Kenney, Dr. Alex Byrd, and Dr. Abhik Roy.

Reliability is the degree in which the measurement can deliver consistent results when administered to a population (Ary et al., 2014). In most studies, a pilot study is used to determine the reliability of the instrument by selecting a small sample from a similar population to test the result of the instrument. In this case, a pilot study was not conducted due to the lack of a similar population of agriculture teachers familiar with West Virginia meat science curriculum. . To combat this issue, the tested and reliable instrument, Science Teaching Efficacy Belief Instrument (STEBI), was used and edited to assess self - efficacy levels on content and outcomes, perceptions of STEM integration, and barriers to meat science integration. This instrument utilizes a 5-point Likert scale that has been used in many research studies to measure science teaching self-efficacy and outcome expectancy of in-service teachers (Stelar: Stem Learning and Research Center, 2020).

For this study, a census of the agricultural teachers in West Virginia was surveyed $(\mathrm{N}=110)$. Sampling and frame errors were avoided due to the fact that a census of the entire 
West Virginia agricultural teacher population was taken. A list of West Virginia agricultural teachers was used to ensure every teacher received the opportunity to participate in this study, and to avoid selection error. The biggest threat to external validity was non-response error. However, this potential error was avoided by using the Dillman's tailored design method which is a set of research-based guidelines to properly distribute a survey. In addition to personally contacting WV SBAE teachers through social media platforms.

\section{Data Collection Techniques}

The Dillman's (2014) method of tailored design was used to distribute this survey. This approach effectively increases the response rate of a survey (Dillman et al., 2014). The implementation of this technique starts with sending participants an email explaining the purpose of the study and why they were chosen to participate in this study. The participant is then sent an invitation email which contains the web-based survey link, and a cover letter explaining the research study and the requirements of their participation. This invitation is then followed by 3 additional emails that remind participants of the survey and its due date. The initial Qualtrics link and cover letter for this survey were sent out on January 26th, 2021. Follow-up emails were sent out to non-respondents on February 2nd, 2021; February 9th, 2021; and February 16th, 2021. The final respondents to take the survey were recorded on February 23th, 2021.

\section{Use of Findings}

The findings of this study will be used to increase confidence and ability of West Virginia secondary agricultural teachers in incorporating STEM components into meat science lessons. Before working to improve the current status of meat science programs throughout West Virginia, we must first know how this subject is taught. Meat science provides an exciting and 
practical opportunity to incorporate STEM components into the existing content to best reach students' learning needs (Ricketts, Duncan, \& Peake, 2006). This study is the foundation to learning ways we can improve meat science course content to deliver more meaningful lessons. 


\section{Chapter 4: Results and Findings}

\section{Purpose of the Study}

The purpose of this study was to describe the current practices used by secondary agricultural teachers in West Virginia regarding instruction of meat science. This includes current methods, choice of topics, depth of topics, their seasonal preference for teaching the subject, and whether teachers use meat science as a context to infuse STEM components into their SBAE program. This study also focused on describing self-efficacy levels related to delivering meat science content, and STEM integration of the current West Virginias BAE teachers.

\section{Objectives}

- Describe the current practices related to secondary meat science education in West Virginia.

- Determine teachers' use of meat science as a context to introduce STEM components into their school-based agricultural education program.

- Describe the self-efficacy levels related to teaching meat science of current West Virginia SBAE teachers.

\section{Demographics}

The respondents were asked specific questions to assist describing the population that could potentially impact their self-efficacy levels, along with decisions to incorporate meat science into their curriculum. These questions included teacher age, gender, years of teaching agricultural education experience, school community area, grade levels taught, and meat science training experience. Table 1 displays that the participants in this descriptive survey consisted of 
19 females (52.80\%) females, 16 males $(44.40 \%)$ and one respondent $(2.80 \%)$ who chose "other."

Table 1

Gender

\begin{tabular}{lcc}
\hline & $f$ & $\%$ \\
\hline Female & 19 & 52.80 \\
Male & 16 & 44.40 \\
Other & 1 & 2.80 \\
\hline
\end{tabular}

Note. $n=36$

The average age of respondents was 39.11 years $(S D=12.58)$, with the oldest respondent indicating they were 63, and the youngest indicating they were 22 years old (shown in Table 2). Respondents were prompted to indicate how many years they had been teaching agricultural education. As shown in Table 2, the years of teaching agricultural education ranged from one year of experience to 39 years of experience. However, the overall average was 14 years $(S D=$ 11.70).

Table 2

Agricultural Educators' Age and Years of Teaching Experience

$n \quad$ Min $\quad$ Max $\quad M \quad S D$


$\begin{array}{llllll}\text { Age } & 36 & 22 & 63 & 39.11 & 12.58\end{array}$

$\begin{array}{llllll}\text { Years of Teaching Experience } & 36 & 1 & 39 & 14.00 & 11.70\end{array}$

Respondents indicated the types of areas that would describe their school community. Table 3 shows that 17 respondents (47.22\%) selected the descriptor, "My school community has at least 2,500 people in the area and has less than 500 people per square mile.” Ten respondents (27.78\%) selected, "My school community has more than 1,000 people per square mile, with a population of more than 50,000 people in the area," and nine respondents (25.00\%) selected "My school community has less than 2,500 people in the area and encompasses a large area of land."

Table 3

Area of the School Community

\begin{tabular}{lll}
\hline & $f$ & $\%$ \\
\hline
\end{tabular}

My school community has at least 2,500 people 17

47.22

the area and has less than 500 people per square miles

My school community has more than 1,000 10 27.78 people per square mile, with a population of more than 50,000 people in the area. 
My school community has less than 2,500 people

in the area and encompasses a large area of land.

Note. $n=36$ (Valid Percent)

Respondents were prompted to select the grade levels they taught in their SBAE

Program. Table 4 displays that all respondents $(f=36,100.00 \%)$ taught 10 th, 11 th, and 12 th

grade students. Thirty-four respondents $(94.44 \%)$ taught $9^{\text {th }}$ grade. Four respondents $(11.11 \%)$

taught $8^{\text {th }}$ grade, one respondent $(2.78 \%)$ taught $7^{\text {th }}$ grade, and one respondent $(2.78 \%)$ taught $6^{\text {th }}$ grade.

Table 4

Grade Levels Taught

f $\%$

$12^{\text {th }}$ Grade

36

100.00

$11^{\text {th }}$ Grade

36

100.00

$10^{\text {th }}$ Grade

36

100.00

$9^{\text {th }}$ Grade

34

94.44

$8^{\text {th }}$ Grade

4

11.11 
$6^{\text {th }}$ Grade

$7^{\text {th }}$ Grade

Note. $n=36$
1

2.78

2.78

\section{Meat Science Experience}

Respondents were asked to select the types of meat science training experience they had received. The majority of the respondents $(f=12,75.00 \%)$ had attended secondary classes which focused on meat science and processing (Table 5). Ten respondents $(62.50 \%)$ indicated they had attended a formal college class focused on meat science and processing, and 10 respondents $(62.50 \%)$ indicated they had attended formal professional development on meat science and processing.

Table 5

Meat Science Training Experience

n $\%$

I attended secondary classes

12

75.00

which focused on meat

science and processing

I attended a formal college

class focused on meat

science and processing 
I have attended formal

professional development on

meat science and processing

Note. $n=16$

\section{Meat Science Practices and Facilities}

All respondents were presented with an item designed to determine whether their SBAE program had access to a meat lab. Twenty-five respondents (59.50\%) said they did have access to a meat lab whether that be at their own school program, or through borrowing from a neighboring schools laboratory (Table 6). It was also found that 17 respondents $(40.50 \%)$ did not have access to a meat lab.

Table 6

Meat Lab Access

\begin{tabular}{lcc}
\hline & $f$ & $\%$ \\
\hline Yes & 25 & 59.50 \\
No & 17 & 40.50 \\
\hline
\end{tabular}

Note. $n=42$ (valid percent)

The respondents who indicated having access to a meat lab were then asked to select the different types of equipment that could be found in their meat lab. This question also provided a text box entry for those who had equipment not found on the list. As shown in Table 7, 23 
respondents (95.83\%) who had a band saw, 23 respondents $(95.83 \%)$ who had a freezer, 23 respondents (95.83\%) who had a grinder, 23 respondents $(95.83 \%)$ who had personal protective equipment (PPE), 23 respondents $(95.83 \%)$ who had processing tables, 23 respondents $(95.83 \%)$ who had a refrigerator, and 23 respondents $(95.83 \%)$ who had a scale. This item also found that 22 respondents $(91.67 \%)$ had a hand saw, 22 respondents $(91.67 \%)$ had a slicer, and 22 respondents $(91.67 \%)$ had a smoker. Of the respondents who indicated to having access to a meat lab, there were 21 respondents $(87.50 \%)$ who had a boning knife, 21 respondents $(87.50 \%)$ who had a vacuum packer, 18 respondents (75.00\%) who had a hanging system, 16 respondents $(67.00 \%)$ who had a breaking saw, and 14 respondents $(58.30 \%)$ who had a breaking knife. There were also 14 respondents $(58.30 \%)$ who had meat tenderizer, 12 respondents $(50.00 \%)$ who had a mixer, 10 respondents $(41.67 \%)$ who had a label maker, and five respondents $(20.83 \%)$ who had a patty maker. Eight respondents $(33.33 \%)$ indicated that they had other equipment beyond the options provided. These eight respondents were asked to list this additional equipment found in their meat lab. This additional equipment included a Colosimo press, a hydraulic piston stuffer, curing and carcass coolers, harvesting floor equipment, a knife sharpener, an assortment of knives, a vacuum tumbler, and an injector.

\section{Table 7}

Equipment in Meat Lab

\begin{tabular}{|c|}
\hline Equipment \\
\hline
\end{tabular}


Freezer

Grinder

Personal Protective Equipment

Processing Tables

Refrigerator

Scale

Hand Saw

Slicer

Smoker

Boning Knife

Vacuum Packer

Hanging System

Breaking Saw

Breaking Knife

Meat Tenderizer

Mixer
23

23

95.83

23

95.83

23

95.83

23

95.83

23

95.83

22

91.67

22

91.67

22

91.67

21

87.50

21

87.50

18

75.00

16

67.00

14

58.30

14

58.30

12 
Label Maker

Other

Patty Maker
10

8

5
41.67

33.33

20.83

Note. $n=24$

Respondents were then prompted with a question to determine whether they taught meat science in their agricultural program. Based upon the responses to this question, the respondents were guided to two different sets of questions through skip logic. Table 8 displays that 14 respondents (32.60\%) "did not teach meat science formally in any of classes, but did participate in the Ham, Bacon and Egg (HBE) show," 14 respondents (32.60\%) "did not teach meat science," 13 respondents (30.20\%) "did teach meat science," and two respondents $(4.70 \%)$ selected "other" for their types of meat science practices. Of these two respondents' answers, common themes were found in their reasoning for selecting "other." This included meat science being taught by another teacher in the program, and meat science being taught at a different time of the year. The teachers who indicated teaching meat science were directed to a section of questions to cater to their experiences, as well as the teachers who indicated to not teaching meat science.

\section{Table 8}

Types of Meat Science Practices 
I do not teach any meat

science but do participate in

the HBE show.

I do not teach meat science

formally

I do teach meat science

13

30.20

Other

2

4.70

\section{Agricultural Educators Teaching Meat Science}

Agricultural educators who indicated that they teach meat science were asked how they taught meat science. The purpose of this question was to determine if they taught meat science as a full course, as a complete unit plan, or an individual lesson from a different unit plan. As shown in to Table 9, six respondents $(50.00 \%)$ who indicated they "teach meat science as a full course," three respondents $(25.00 \%)$ who indicated they "teach meat science as an individual lesson in a different unit plan," and three respondents $(25.00 \%)$ who indicated they "teach meat science as a complete unit".

\section{Table 9}

How Meat Science is Taught 


\begin{tabular}{llc}
\hline & $f$ & $\%$ \\
\hline I teach it as a full course & 6 & 50.0 \\
I teach it as an individual lesson in a different & 3 & 25.0 \\
unit plan & & \\
I teach a complete unit & 3 & 25.0 \\
\hline
\end{tabular}

Note. $n=12$ (Valid Percent)

Agricultural educators who indicated that they teach meat science were asked to select the different types of teaching methods they used to teach meat science. Table 10 shows that the teaching method that was used the most by the West Virginia SBAE teachers for meat science was demonstration $(f=11,91.67 \%)$. This was followed by lecture $(f=10,83.33 \%)$, discussion/questioning $(f=9,75.00 \%)$, problem solving $(f=8,67.00 \%)$, and computer-aided instruction $(f=7,58.33 \%)$. This study also found that some respondents used brainstorming $(f=$ $6,50.00 \%)$, field trips $(f=6,50.00 \%)$, independent study $(f=5,41.67 \%)$, supervised study $(f=$ $5,41.67)$, instructional posters $(f=5,41.67 \%)$, experiments $(f=4,33.33 \%)$, cooperative learning $(f=4,33.33 \%)$, and guest speakers $(f=4,33.33 \%)$ to teach meat science. However, no teachers used case studies $(f=0,0.00 \%)$ to teach meat science.

\section{Table 10}

\section{Teaching Methods}

Teaching Methods

f $\%$

Demonstration

11

91.67 
Lecture

83.33

Discussion/ Questioning

75.00

Problem Solving

8

67.00

Computer Aided Instruction

58.33

Brainstorming

6

50.00

Field Trips

Supervised Study

Experiments

Cooperative learning

Guest Speakers

4

Case Studies

0

0.00

Note. $n=12$

Agricultural educators who indicated that they teach meat science were asked to select how in-depth they taught a list of meat science topics in terms of how detailed the content was provided. This question utilized a 5 -point Likert type scale ranging from $5=$ very in-depth, to $1=$ none at all. The averages of the responses were calculated to determine how in-depth certain topics in meat science were taught by using IBM statistical Package for Social Sciences (SPSS) 
version 27 .

According to Table 11, the meat science topics that were taught the most in-depth by the West Virginia SBAE teachers were both retail, and wholesale cuts, with the same mean and standard deviations $(M=4.67, S D=0.65)$. This was followed closely by fabrication $(M=4.67$, $S D=0.78$ ), with a similar mean, but higher standard deviation. The next topic taught in the most depth was sanitation $(M=4.50, S D=0.80)$, followed by value added processing $(M=4.42, S D$ $=1.08)$, curing and smoking $(M=4.33, S D=1.07)$, fresh meat properties $(M=3.92, S D=1.17)$, and hazard analysis critical control point (HACCP) $(M=3.83, S D=1.12)$. The topics that were taught the least in-depth were quality grades $(M=3.50, S D=0.91)$, meat color $(M=3.50, S D=$ $1.09)$, yield grades $(M=3.42, S D=1.08)$, food groups/nutrition $(M=3.00, S D=1.04)$, byproducts $(M=2.92, S D=0.52)$, history of meat $(M=2.75, S D=0.75)$ and meats and world hunger $(M=2.17, S D=0.94)$.

\section{Table 11}

Depth of Meat Science Topics Taught

\begin{tabular}{lccc}
\hline & $n$ & $M$ & $S D$ \\
\hline Retail cuts & 12 & 4.67 & 0.65 \\
Wholesale cuts & 12 & 4.67 & 0.65 \\
Fabrication & 12 & & 0.78 \\
& & 4.67 & \\
Sanitation & 12 & 4.50 & 0.80
\end{tabular}




\begin{tabular}{|c|c|c|c|}
\hline Value added & 12 & 4.42 & 1.08 \\
\hline \multicolumn{4}{|l|}{ processing/sausage } \\
\hline Curing and smoking & 12 & 4.33 & 1.07 \\
\hline Fresh meat properties & 12 & 3.92 & 1.17 \\
\hline HACCP & 12 & 3.83 & 1.12 \\
\hline Quality grades & 12 & 3.50 & 0.91 \\
\hline Meat color & 12 & 3.50 & 1.09 \\
\hline Yield grades & 12 & 3.42 & 1.08 \\
\hline Food Groups/Nutrition & 12 & 3.00 & 1.04 \\
\hline Byproducts & 12 & 2.92 & 0.52 \\
\hline History of meat & 12 & 2.75 & 0.75 \\
\hline Meats and world & 12 & 2.17 & 0.94 \\
\hline
\end{tabular}

Note. $n=12$ (Valid N listwise)

Agricultural educators who indicated that they teach meat science were asked to select how in-depth they taught different species in terms of how detailed the content was provided. This question utilized a 5-point Likert type scale, ranging from $5=$ very in-depth, to $1=$ not indepth at all. The averages of the responses were calculated to determine how in-depth certain topics in meat science were taught by using IBM statistical Package for Social Sciences (SPSS) 
version 27 .

Table 12 shows that the species that was taught with the most depth by the West Virginia SBAE teachers was pork $(M=4.67, S D=0.89)$. Pork was followed by beef $(M=4.33, S D=$ $0.89), \operatorname{lamb}(M=3.08, S D=1.08)$, poultry $(M=3.00, S D=1.13)$, and venison $(M=2.58, S D=$ 1.56). The species that were taught least in depth were goats $(M=2.42, S D=1.17)$, followed by veal $(M=1.92, S D=1.08)$, and fish $(M=1.83, S D=0.94)$.

\section{Table 12}

Depth of Meat Science Species Taught

\begin{tabular}{|c|c|c|c|}
\hline Species & $n$ & $M$ & $S D$ \\
\hline Pork & 12 & 4.67 & 0.89 \\
\hline Beef & 12 & 4.33 & 0.89 \\
\hline Lamb & 12 & 3.08 & 1.08 \\
\hline Poultry & 12 & 3.0 & 1.13 \\
\hline Venison & 12 & 2.58 & 1.56 \\
\hline Goats & 12 & 2.42 & 1.17 \\
\hline Veal & 12 & 1.92 & 1.08 \\
\hline Fish & 12 & 1.83 & 0.94 \\
\hline
\end{tabular}

Note. $n=12$ (Valid N listwise)

Agricultural educators who indicated that they teach meat science were asked how many 
days out of each month they taught meat science. The purpose of this question was to determine which month meat science was being taught with the highest frequency. This question allowed respondents to reply by typing the number of days they taught meat science out of each month into the corresponding box. These numbers were then calculated to determine the average number of days meat science was being taught each month using IBM Statistical Package for Social Sciences (SPSS) version 27.

As shown in Table 13, the month in which meat science was taught the most days by the West Virginia SBAE teachers was November $(M=8.27, S D=7.75)$. This was followed by the months $\operatorname{March}(M=8.25, S D=8.39)$, October $(M=7.67, S D=8.64)$, February $(M=7.50, S D$ $=8.25)$, and April $(M=6.75, S D=8.14)$. The next months in which meat science was taught the most were January $(M=6.58, S D=7.81)$, September $(M=6.50, S D=9.06)$, December $(M=$ $6.42, S D=6.57)$, May $(M=4.67, S D=7.17)$, and August $(M=1.67, S D=3.26)$.

\section{Table 13}

Average Number of Days Spent Teaching Meat Science per Month

\begin{tabular}{lccc}
\hline & $n$ & $M$ & $S D$ \\
\hline November & 11 & 8.27 & 7.75 \\
March & 12 & 8.25 & 8.39 \\
October & 12 & & 8.64 \\
February & 12 & 7.67 & 8.25 \\
April & 12 & 7.50 & 8.14
\end{tabular}




$\begin{array}{lccc}\text { January } & 12 & 6.58 & 7.81 \\ \text { September } & 12 & 6.50 & 9.06 \\ \text { December } & 12 & 6.42 & 6.57 \\ \text { May } & 12 & 4.67 & 7.17 \\ \text { August } & 12 & 1.67 & 3.26\end{array}$

Note. $n=12$

\section{Agricultural Educators who do Not Formally Teach Meat Science}

The agricultural educators who indicated that they do not teach meat science were asked to select the reasons why. The purpose of this question was to determine the main reasons meat science was not being taught. This question allowed respondents to choose reasons from a set list of explanations for not teaching meat science. In addition, this question also provided a text box for respondents to explain in greater detail if needed.

As illustrated in Table 14, the main reason several teachers did not teach meat science was a lack of facilities $(f=13,86.67 \%)$. This was followed by my decision $(f=6,40.00 \%)$, situational decision $(f=5,33.33 \%)$, "administration decision $(f=3,20.00 \%)$, school and community expectations $(f=3,20.00 \%)$. There were seven respondents $(46.67 \%)$ who selected "other." The responses for this option included: "There is no need for meat science education in the community," "insufficient funds, time, and teachers," "focus on other concentrations," and "it has not been offered".

\section{Table 14}

Reasons for Not Teaching Meat Science 


\begin{tabular}{lcc}
\hline & $f$ & $\%$ \\
\hline Lack of Facilities & 13 & 86.67 \\
Other & 7 & 46.67 \\
My Decision & 6 & 40.00 \\
Situational Decision & 5 & 33.33 \\
Administration Decision & 3 & 20.00 \\
School and Community Expectations & 3 & 20.00 \\
\hline
\end{tabular}

Note. $n=15$

\section{STEM Efficacy}

Respondents were asked to select the answer that best described their confidence in their ability to teach STEM components. This question utilized a 5-point Likert type scale, where $5=$ completely confident, 4 = fairly confident, 3 = somewhat confident, 2 = slightly confident, and 1 $=$ not confident at all. The responses were calculated to determine the overall mean of confidence in the teacher's ability to teach in each of the STEM components using IBM Statistical Package for Social Sciences (SPSS) version 27. Table 15 displays that the West Virginia SBAE teachers were most confident in teaching science $(M=4.18, S D=0.65)$. This was followed by technology $(M=3.95, S D=0.84)$, math $(M=3.79, S D=1.02)$, and engineering $(M=3.05, S D$ $=1.14)$.

\section{Table 15}


Confidence in Ability to Teach STEM Components

\begin{tabular}{lccc}
\hline & $n$ & $M$ & $S D$ \\
\hline Science & 38 & 4.18 & 0.65 \\
Technology & 38 & 3.95 & 0.84 \\
Math & 38 & 3.79 & 1.02 \\
Engineering & 38 & 3.05 & 1.14 \\
\hline
\end{tabular}

Note. $n=38$ (Valid $\mathrm{N}$ listwise)

\section{Integrating STEM into Meat Science}

Respondents who taught meat science were asked to identify their general perspectives surrounding integrating STEM into meat science. This question utilized a 5-point Likert type scale that included $5=$ strongly agree, $4=$ agree, $3=$ uncertain, $2=$ disagree and $1=$ strongly disagree. Responses were calculated using IBM statistical Package for Social Sciences (SPSS) version 27.

Table 16 shows the statement with the highest mean which indicated the highest level of agreement was "Integrating STEM components into the meat science program requires more preparation time than teaching a more traditional curriculum" $(M=3.75, S D=0.97)$. This was followed by the statements " Students are better prepared in science after they completed a course in agricultural education that integrates STEM components" ( $M=3.67, S D=0.78)$, "Integrating STEM components into meat science classes increases the ability to teach students to solve problems" $(M=3.58, S D=1.00)$, and "Students are more aware of the connection between scientific principles and agriculture when STEM components are an integral part of 
their instruction in agricultural education." $(M=3.50, S D=1.00)$. The statements with the next highest means were "STEM components are easier for students to understand when STEM is integrated into the meat science program" $(M=3.33, S D=1.23)$, "Students learn more about meat science when STEM components are an integral part of their instruction" $(M=3.17, S D=$ 1.12), and "Students are more motivated to learn when STEM components are integrated into the meat science program" $(M=3.17, S D=1.12)$. The statements with the lower average of means was "Meat science concepts are easier for students to understand when STEM components are integrated into the meat science program" $(M=3.17, S D=1.12)$, "Integrating STEM components into the meat science curriculum more effectively meets the needs of special population students (i.e. learning disabled)" $(M=3.08, S D=1.00)$, "It is more appropriate to integrate STEM components in advanced courses than into introductory courses" $(M=3.08, S D$ $=0.79$ ), and "Less effort is required to integrate STEM in advanced courses as compared to introductory courses" $(M=2.92, S D=0.79)$.

\section{Table 16}

Perception of integrating STEM components into meat science

n $\quad M \quad S D$

Integrating STEM components into the meat science 12

program requires more preparation time than teaching a more traditional curriculum. 
Students are better prepared in science after they

12

0.78

completed a course in agricultural education that integrates STEM components.

Integrating STEM components into meat science

classes increases the ability to teach students to solve problems.

Students are more aware of the connection between scientific principles and agriculture when STEM components are an integral part of their instruction in agricultural education.

STEM components are easier for students to

understand when STEM is integrated into the meat science program.

Students learn more about meat science when STEM components are an integral part of their instruction.

Students are more motivated to learn when STEM components are integrated into the meat science program. 
Meat science concepts are easier for students to

understand when STEM components are integrated

into the meat science program.

Integrating STEM components into the meat science

curriculum more effectively meets the needs of special

population students (i.e. learning disabled).

It is more appropriate to integrate STEM components

in advanced courses than into introductory courses.

Less effort is required to integrate STEM in advanced

12

2.92

0.79

courses as compared to introductory courses.

Note. $n=12$

\section{Implemented Integration of STEM}

Respondents who do teach meat science were asked if they had integrated STEM components into their meat science instruction. Table 17 displays that seven respondents $(53.85 \%)$ indicated that "they had integrated STEM into their meat science instruction". This study also found that five respondents $(38.46 \%)$ had "not integrated STEM components into their meat science instruction".

\section{Table 17}

Integration of STEM 
Yes

No
7

5
53.85

38.46

Note. $n=12$ (Valid Percent)

\section{Self - Efficacy related to teaching meat science}

Respondents were asked to select how confident they were in their knowledge on certain topics related to meat science. This question utilized a 5-point Likert type scale where $5=$ extremely knowledgeable, $4=$ very knowledgeable, $3=$ moderately knowledgeable, and $2=$ slightly knowledgeable and $1=$ not knowledgeable at all. Responses were calculated to determine the overall mean of confidence knowledge in each of the meat science topics using IBM statistical Package for Social Sciences (SPSS) version 27. For this question higher means equal higher confidence.

This descriptive study found that respondents were most confident in their knowledge of teaching "sanitation" $(M=3.90, S D=1.00)$. This was followed by "wholesale cuts" $(M=3.54$, $S D=1.07)$, "retail cuts" $(M=3.51, S D=1.02)$, and "value added processing" $(M=3.44, S D=$ 1.17). The topics that were the next highest in confidence were "byproducts" $(M=3.31, S D=$ $0.86)$, "curing and smoking" $(M=3.31, S D=1.24)$, "meat color" $(M=3.28, S D=1.10)$, "yield grades" $(M=3.26, S D=1.09)$, and "quality grades" $(M=3.23, S D=1.09)$. The topics in which teachers were moderately confident in teaching were "fabrication" $(M=3.18, S D=1.28)$, "food/nutrition" $(M=3.13, S D=0.95)$, and "fresh meat properties" $(M=3.10, S D=1.10)$. The topics with the least amount of confidence levels were "meats and world hunger" $(M=3.00, S D$ $=1.05)$, "hazard analysis critical control point $(\mathrm{HACCP})$ " $(M=2.97, S D=1.22)$, and "history 
of meat" $(M=2.92, S D=1.04)$. Table 18 displays these results.

\section{Table 18}

Confidence in knowledge of meat science topics

\begin{tabular}{|c|c|c|c|}
\hline Meat Science Topics & $n$ & $M$ & $S D$ \\
\hline Sanitation & 39 & 3.90 & 1.00 \\
\hline Wholesale cuts & 39 & 3.54 & 1.07 \\
\hline Retail cuts & 39 & 3.51 & 1.02 \\
\hline Value Added Processing & 39 & 3.44 & 1.17 \\
\hline Byproducts & 39 & 3.31 & 0.86 \\
\hline Curing and Smoking & 39 & 3.31 & 1.24 \\
\hline Meat Color & 39 & 3.28 & 1.10 \\
\hline Yield Grades & 39 & 3.26 & 1.09 \\
\hline Quality Grades & 39 & 3.23 & 1.09 \\
\hline Fabrication & 39 & 3.18 & 1.28 \\
\hline Food/Nutrition & 39 & 3.13 & 0.95 \\
\hline
\end{tabular}


Fresh Meat Properties

Meats and World

Hunger

HACCP

History of Meat
39

39

3.00

1.05

3.10

39

(1.05

3.00

39

2.97

1.22

Note. $n=39$ (Valid N Listwise)

2.92

Respondents were asked to rank species of meat products based on their confidence in teaching them. This question allowed the respondents to click a species with their cursor and drag it to a place on the list that described their confidence and drop it there. This list explained that the species placed in the number one spot would indicate the species they were most confident in teaching, and the species placed in the number eight spot would indicate the species there were least confident in teaching. Furthermore, in this question lower means indicate higher levels of confidence. These placings were then averaged and analyzed with IBM statistical Package for Social Sciences (SPSS) version 27.

Table 19 displays the species West Virginia SBAE teachers felt most confident teaching was "pork" $(M=2.14, S D=1.62)$. Pork was closely followed by "beef' $(M=2.16, S D=0.99)$, "poultry" $(M=3.84, S D=1.88)$, and "venison" $(M=4.14, S D=2.31)$. The species respondents were least confident in teaching were "lamb" $(M=5.22, S D=1.32)$, "goat" $(M=5.84, S D=$ 1.28), "fish" $(M=6.14, S D=1.81)$, and "veal" $(M=6.54, S D=1.64)$. 
Ranking Confidence of Species Taught

\begin{tabular}{lccc}
\hline & $n$ & $M$ & $S D$ \\
\hline Pork & 37 & 2.14 & 1.62 \\
Beef & 37 & 2.16 & 0.99 \\
Poultry & 37 & 3.84 & 1.88 \\
Venison & 37 & 4.14 & 2.31 \\
Lamb & 37 & 5.22 & 1.32 \\
Goats & 37 & 5.84 & 1.28 \\
Fish & 37 & 6.14 & 1.81 \\
Veal & 37 & 6.54 & 1.64 \\
\hline
\end{tabular}

Note. $n=37$ (Valid $\mathrm{N}$ listwise) lower means $=$ higher levels of confidence in this context

\section{Self efficacy levels of teaching Meat Science}

Respondents were asked to identify their Self-efficacy levels in teaching meat science. This question utilized a 5-point Likert type scale where $5=$ strongly agree, $4=$ agree, $3=$ uncertain, 2 = disagree, and $1=$ strongly disagree. The responses were calculated to determine the overall self-efficacy levels in teaching meat science using IBM Statistical Package for Social Sciences (SPSS). For this question, higher means indicate higher agreement levels. In addition, there were two questions that were reverse coded to assist in the reliability of the instrument. These two questions were marked with a *. 
As seen in Table 20, the statement with the highest mean was "*Given a choice, I would not invite the principal to evaluate my meat science teaching*" $(M=3.76, S D=1.23)$. This was followed by the statements "I am typically able to answer student's meat science questions" ( $M$ $=3.70, S D=1.02)$, "I am continually finding better ways to teach meat science concepts" $(M=$ $3.57, S D=0.87$ ), and "I understand meat science curriculum concepts well enough to be effective in teaching" $(M=3.49, S D=1.04)$. The statements with the least amount of confidence were "I know the steps necessary to teach meat science concepts effectively" $(M=$ $3.46, S D=1.04)$, and "*Given a choice, I would not invite the principal to evaluate my meat science curriculum*" $(M=2.89, S D=0.85)$.

Table 20

Self-Efficacy Levels of Teaching Meat Science

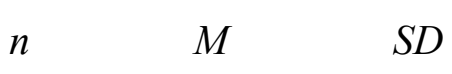

Given a choice, I would not invite the principal to evaluate 37

3.76

1.23

my meat science teaching. *

I am typically able to answer student's meat science 37 questions.

I am continually finding better ways to teach meat science 37 3.57 0.87 concepts.

I understand meat science curriculum concepts well 37 enough to be effective in teaching. 
I know the steps necessary to teach meat science concepts effectively.

Given a choice, I would not invite the principal to evaluate my meat science curriculum. *

Note. $n=37$ The reverse coded statements are marked with a *

\section{Self-Efficacy in Outcome Expectancy in Meat Science}

Respondents were asked to indicate their self-efficacy levels in the outcomes of teaching meat science. This question utilized a 5 -point Likert type scale where $5=$ strongly agree, $4=$ agree, $3=$ uncertain, $2=$ disagree and $1=$ strongly disagree. The responses were calculated to determine the overall self-efficacy levels in the outcomes of teaching meat science using IBM statistical Package for Social Sciences (SPSS) version 27. For this question, higher means indicate higher agreement levels. In addition, there were four questions that were reverse coded to assist in the reliability of the instrument. These four questions were marked with a *.

Table 21 shows the statement with which the West Virginia SBAE teachers had the highest level of self-efficacy was, "The inadequacy of a student's meat science background can be overcome by good teaching" ( $M=3.97, S D=0.94)$. This statement was followed by the statements, "When meat science scores of students improve, it is most often due to their teacher having found a more effective teaching approach" $(M=3.75, S D=0.69)$, "Students achievement in meat science is directly related to their teacher's effectiveness in curriculum planning" $(M=3.47, S D=0.77)$, and "When a low-achieving child progresses in meat science, it is usually due to extra attention given by the teacher" $(M=3.42, S D=0.81)$. The statements 
that respondents moderately agreed with were "*Effectiveness in meat science teaching has little influence on the achievement of students with low motivation*" $(M=3.22, S D=0.76)$, "When a student does better than usual on meat science exams, it is often because the teacher exerted a little extra effort" $(M=3.11, S D=0.85)$, and "**Increased effort in teaching meat science produces little change in some students' meat science achievement*" $(M=3.00, S D=0.79)$. The statements in which teachers had the least amount of agreement were "If students are underachieving in a meat science course, it is most likely due to ineffective teaching" ( $M=2.78$, $S D=0.76)$, "*Even teachers with good meat science teaching abilities cannot help some kids learn meat science concepts*” $(M=2.67, S D=1.01)$, and "*The low meat science achievement of some students cannot generally be blamed on their teachers*" $(M=2.47, S D=0.88)$.

\section{Table 21}

Self-Efficacy Levels of the Outcomes of Teaching Meat Science

$n \quad M \quad S D$

The inadequacy of a student's meat science background 36

3.97

0.94 can be overcome by good teaching.

When meat science scores of students improve, it is 36 3.75 0.69 most often due to their teacher having found a more effective teaching approach. 
Students achievement in meat science is directly

related to their teacher's effectiveness in curriculum

planning.

When a low-achieving child progresses in meat

science, it is usually due to extra attention given by the teacher.

Effectiveness in meat science teaching has little influence on the achievement of students with low motivation. *

When a student does better than usual on meat science exams, it is often because the teacher exerted a little extra effort.

Increased effort in teaching meat science produces

little change in some students' meat science achievement. *

If students are underachieving in a meat science course, it is most likely due to ineffective teaching. abilities cannot help some kids learn meat science concepts. * 
The low meat science achievement of some students 36 2.47 0.88 cannot generally be blamed on their teachers*

Note. $n=36$ (Valid $\mathrm{N}$ listwise) The reverse coded statements are marked with a *.

\section{Barriers to Integrating Meat Science Curriculum}

Respondents were asked to indicate the items they consider a barrier in regard to integrating meat science into the curriculum. This question utilized a 5-point Likert type scale where $5=$ strongly agree, $4=$ agree, $3=$ uncertain, $2=$ disagree, and $1=$ strongly disagree. The responses were calculated to determine the barriers West Virginia SBAE teachers have in regard to integrating meat science into their curriculum using IBM Statistical Package for Social Sciences (SPSS). For this question, higher means indicate higher agreement levels with items that are considered barriers.

As shown in Table 22, the barrier with the highest mean was "There is insufficient funding" ( $M=3.47, S D=1.25)$. This was followed by the statements "I don't have the necessary materials" $(M=3.33, S D=1.39)$, "There is insufficient time and support to plan for implementation" $(M=3.25, S D=1.18)$, and "I have a lack of experience in meat science integration" $(M=3.17, S D=1.22)$. The statements with which teachers moderately agreed were, "Insufficient background in meat science content" $(M=3.11, S D=1.21)$, "There is a lack of meat science related jobs in the local community" $(M=3.11, S D=1.30)$, "I have concerns about a large class size" $(M=3.08, S D=1.30)$, "There is a lack of integrated meat science curriculum in courses I teach" $(M=3.00, S D=1.01)$, and "There is a lack of parent and community support for meat science integration" $(M=2.69, S D=1.04)$. The statements with the least amount of agreement were, "I am reluctant to diminish emphasis on agricultural production" ( $M=2.61, S D$ 
$=1.10)$, "There is a lack of support from local science teacher(s)" $(M=2.50, S D=1.06)$, "There is a lack of administrative support for meat science integration" $(M=2.42, S D=1.00)$, "I don't believe that meat science integration is necessary" $(M=2.33, S D=0.99)$, "I have doubts about students' capacity to handle material" $(M=2.22, S D=0.96)$, "I have concerns about discipline" $(M=2.19, S D=0.92)$, and "I have tried integrating meat science and it was unsuccessful" $(M=$ $1.94, S D=0.67)$

Table 22

Barriers of Integrating Meat Science into Curriculum

n $\quad M \quad S D$

There is insufficient funding 36

3.47

1.25

I don't have the necessary materials

36

3.33

1.39

There is insufficient time and support to plan for

36 implementation

I have a lack of experience in meat science 35 integration

Insufficient background in meat science content 35 3.11

There is a lack of meat science related jobs in the 36 3.11 1.30 local community 
I have concerns about a large class size

There is a lack of integrated meat science curriculum in courses I teach

There is a lack of parent and community support for meat science integration

I am reluctant to diminish emphasis on agricultural production

There is a lack of support from local science teacher(s)

There is a lack of administrative support for meat science integration

I don't believe that meat science integration is necessary

I have doubts about students' capacity to handle material

I have concerns about discipline

I have tried integrating meat science and it was unsuccessful
36

36

3.00

1.01

36

2.69

1.04

36

36

2.50

1.06

36

2.42

1.00

36

2.33

0.99

36

2.22

0.96

36

2.19

0.92

36

1.94

0.67

Note. $n=36$ 


\section{Professional Development}

Respondents were asked to select any type of professional development they felt would help them to be more confident in teaching meat science. This question allowed respondents to choose from a set list of professional development topics that would help West Virginia SBAE teachers to feel more confident in teaching meat science. In addition, this question also provided a text box to explain in greater detail if needed.

Table 23 displays that every respondent $(f=30,100.00 \%)$ selected "Meat Science Professional Development" as a resource that would increase their sense of confidence in teaching meat science. 11 respondents (36.67\%) selected "Incorporating STEM components into meat science," nine respondents (30.00\%) selected" STEM Professional Development," and one respondent (3.33\%) selected "other." The respondent who selected "other" explained their response by stating, "Offering credits to attend the summer classes offered at Flying W farms [A family owned business that provides fresh produce, and meats to the community. While operating with a facility designed by Dr. Temple Grandin] in Burlington, West Virginia."

Table 23

Professional Development

\begin{tabular}{lcc}
\hline & $f$ & $\%$ \\
\hline Meat science professional & 30 & 100.00 \\
development & &
\end{tabular}


Incorporating STEM

components into meat

science

STEM professional

development

Other

Note. $n=30$
11

36.67

9

30.00

1

3.33 


\section{Chapter 5: Conclusions and Recommendations}

\section{Purpose of the Study}

The purpose of this study was to describe current practices being used by West Virginia's secondary agricultural teachers regarding instruction in the meat laboratory. This includes current methods, choice and depth of topics, seasonal preference for teaching meat science and teachers' levels of integration of STEM components in their SBAE program. This study also describes self-efficacy levels of current West Virginia SBAE teachers delivering meat science content.

\section{Objectives}

- Describe current practices related to delivering secondary meat science education in West Virginia.

- Determine teachers' use of meat science as a context to introduce STEM components into their School-Based Agricultural Education Program.

- Describe self-efficacy levels related to teaching meat science of current West Virginia school-based agricultural education teachers.

\section{Summary of Findings}

The target population for this research study was comprised of West Virginia SBAE teachers in the 2020-2021 school year. For this study, a census of all available agricultural teachers in West Virginia (108 agricultural teachers and 81 SBAE) was asked to participate. There was a total of 44 usable responses for a final response rate of $40 \%$.

\section{Demographics}

In order to gain a better understanding of the population, respondents were prompted with 
specific demographic questions to assist in describing the population. The responses to these questions could potentially impact the respondents' self-efficacy levels, along with decisions to incorporate meat science into their curriculum. These questions included teacher age, gender, years of teaching agricultural education, school community area, grade levels taught, and meat science training experience. This descriptive study found that the average age of the respondents was 39.11 years $(S D=12.58)$, with the oldest respondent being 63 , and the youngest being 22 years old. A little over half of the respondents were females $(52.80 \%)$. The average years of teaching agricultural education was $14(S D=11.70)$ and ranged from one year of experience to 39 years of experience. The majority $(47.22 \%)$ of the respondent's school community has at least 2,500 people in the area and had less than 500 people per square mile. Every respondent taught grades 12 through $10(100.00 \%)$, while a majority (94.44\%) taught grade 9 . The majority of the respondents (75\%) had attended secondary classes which focused on meat science and processing.

\section{Research Objective One}

The purpose of research objective one was to describe the current practices related to secondary meat science education in West Virginia. Knowing the current practices of meat science will assist in understanding how meat science is currently being taught in West Virginia SBAE programs, and determining if professional development opportunities are needed. 
Facilities. This study found the majority of respondents do not teach meat science formally in a class. However, half of those respondents who do not teach meat science do participate in the Ham, Bacon, and Egg show. Approximately one-third of the respondents teach meat science. It should also be noted that the majority $(59.50 \%)$ of the participants have access to a meat lab.

The teachers who indicated having access to a meat lab $(f=25,59.50 \%)$ were asked to indicate the equipment that could be found in the meat lab. The majority of the respondents had a band saw (95.83\%), freezer (95.83\%), grinder (95.83\%), personal protective equipment (PPE) (95.83\%), processing tables (95.83\%), refrigerator (95.83\%), scales (95.83\%), hand saw (91.67), slicer (91.67\%), smoker (91.67\%), boning knife (87.50\%), vacuum packer (87.50\%), hanging system $(75.00 \%)$, breaking saw $(67.00 \%)$, breaking knife $(58.30 \%)$, meat tenderizer $(58.30 \%)$ and a mixer (50.00\%). Less than half of the respondents had a label maker $(41.67 \%)$, and a patty maker (20.83\%). Eight respondents selected "other" and were asked to provide any additional equipment found in their meat lab that was not on the list. Their additional equipment included: Colosimo press, hydraulic piston stuffer, curing and carcass coolers, harvesting floor equipment, knife sharpener, variety of knives, vacuum tumbler, and an injector.

Teaching Practices. Half of the respondents who do teach meat science teach it as a full course $(50 \%)$. One quarter of the teachers who teach meat science teach it as a complete unit, and the remaining quarter teach it as an individual lesson in a different unit plan. The teaching method used the most frequently was demonstration (91.67\%), which was closely followed by lecture $(83.33 \%)$, discussion/questioning $(75.00 \%)$, and problem solving $(67.00 \%)$. The leastused methods were case studies $(0.00 \%)$, guest speakers $(33.33 \%)$, cooperative learning $(33.33 \%)$ and experiments (33.33\%). 
This descriptive study found that the meat science topics which were taught the most indepth in terms of how detailed the content was provided by the West Virginia SBAE teachers were wholesale cuts $(M=4.67, S D=0.65)$ and retail cuts $(M=4.67, S D=0.65)$. These were closely followed by fabrication $(M=4.67, S D=0.78)$, sanitation $(M=4.50, S D=0.80)$, value added processing $(M=4.42, S D=1.08)$, and curing and smoking $(M=4.33, S D=1.07)$. The meat science topics which were taught in the least depth were meat and world hunger $(M=2.17$, $S D=0.94)$, and the history of meat $(M=2.75, S D=.075)$. This could be the result of a higher focus on delivering meat processing, grading, and chemical reactions in higher-level professional development courses.

The species of animal that was taught the most in-depth in terms of how detailed the content was provided, was pork $(M=4.67, S D=0.89)$, followed by beef $(M=4.33, S D=0.89)$. The species of animal that was taught in the least depth was fish $(M=1.83, S D=0.94)$, followed by veal $(M=1.92, S D=1.08)$. This could be the result of West Virginia SBAE teachers choosing to highlight species-specific knowledge to prepare students for the Ham Bacon and Egg Show. Another potential factor is the diversity of learning experiences offered through studying pork as opposed to other species; during the curing process, pork is a species that is available and offers students the opportunity to see and learn how to process this species. In addition, cow and calf operations make up $21 \%$ of the agricultural receipts in the state of West Virginia (Bushel, 2021). Because of this, beef is another species that is more readily available to teachers across the state.

Meat science was taught the most frequently in the month of November $(M=8.27, S D=$ 7.75). This finding also aligns with the requirements for the HBE show as market hogs used for the HBE show are butchered at the end of October. The product is then returned back to the 
school for further processing at the beginning of November. At this time, teachers will be working to cure hams properly, process the remaining portion of the carcass, and freeze the bacons. The month with the next highest number of days spent teaching meat science was March $(M=8.25, S D=8.39)$. This result also aligns with the HBE process, due to the fact the majority of the local, regional, and state sales occur in March or April. During the month of March, teachers work to trim and smoke hams and bacons properly and prepare for the upcoming show. When prompted to explain why they do not teach meat science, the majority of those teachers indicated "A lack of facilities" $(86.67 \%)$ as the reason for not pursuing this topic. This was followed by the option "other," $(46.67 \%)$ which gave the participant the opportunity to write in their answers. Some of their answers included: "There is no need for meat science education in the community," "insufficient funds, time, and teachers," "focused on other concentrations" and "it has not been offered." This could be the result of the West Virginia agriculture teachers making their lessons and program more practical and applicable to the needs of the surrounding community. Agricultural education was founded on the ideal that it would provide useful and practical information to the community. There are certain areas in West Virginia in which the implementation of meat science education may not be practical or useful to the students and community.

\section{Research Objective Two}

The purpose of research objective two was to determine teachers' use of meat science as a context to introduce STEM components into their school-based agricultural education Program. In order to assess this objective, survey items assessed respondents' current STEM integration, personal confidence in their ability towards teaching STEM components, and perceptions of integrating STEM into meat science. Some of these questions for this section utilized a 5-point 
Likert scale with $5=$ Strongly agree and $1=$ Strongly disagree.

The majority of the West Virginia SBAE teachers who do teach meat science had already integrated STEM into their meat science instruction (58.33\%). However, $41.67 \%$ had not integrated STEM into their meat science instruction. The proximity of these results could be due to lower self-efficacy levels of teachers in their integration of STEM components. While a slight majority of teachers have worked to implement STEM into their meat science curricula, other teachers may not have the time or material to teach STEM components to students, or might identify STEM as a technique they are not as efficacious in.

This descriptive study also found that the West Virginia SBAE teachers were most confident in teaching science $(M=4.18, S D=0.65)$ and technology $(M=3.95, S D=0.84)$, with relatively high mean scores. However, respondents were least confident in teaching math $(M=$ $3.79, S D=1.02$ ) and engineering, which had the lowest mean of 3.05 out of 5 . These results confirm the research of R. Hendrix (2019), who also found that agriculture teachers generally had higher teaching efficacy scores regarding science and technology, and lower teaching efficacy scores regarding engineering and mathematics.

When asked about their perceptions of integrating STEM components into their meat science curriculum, the overall means were located in the "uncertain" category. The item with the highest mean of 3.75 out of 5 stated, "Integrating STEM components into the meat science program requires more preparation time than teaching a more traditional curriculum.” Although this statement is in the "uncertain" category, it is leaning towards agreement, meaning respondents are more likely to spend more time creating more meaningful lessons regarding STEM components. This statement was closely followed by "Students are better prepared in science after they completed a course in agricultural education that integrates STEM 
components," which had a mean of 3.67 out of 5. This can be interpreted as teachers agreeing that integrating STEM into agricultural education can benefit students in future science classes. The statement with the lowest mean of 2.92 out of 5 stated, "Less effort is required to integrate STEM in advanced courses as compared to introductory courses.” Teachers disagree with the statement that it takes less effort to integrate STEM in more advanced classes than introductory classes. It can be inferred that overall, the West Virginia SBAE teachers agree that integrating STEM components into meat science courses is beneficial to students in better understanding concepts from other core classes; however, it does take extra effort to prepare on the teacher's part.

\section{Research Objective Three}

The purpose of research objective three, was to describe the self-efficacy levels of current West Virginia SBAE teachers related to teaching meat science. Self-efficacy refers to the amount of belief one has in their abilities to reach their goals and meet the challenges which are presented. In this study, the ultimate challenge is to effectively teach meat science in a way that is meaningful to students. The respondents were asked specific questions related to confidence in teaching meat science topics, confidence in teaching difference species processing, self-efficacy levels in teaching meat science, self-efficacy levels of the outcome expectancy in teaching meat science, and barriers to integrating meat science into their curriculum.

The West Virginia SBAE teachers were presented with a list of meat science topics and asked to select how confident they were in their content knowledge in order to teach the topic. This question utilized a 5-point Likert type scale with 5= Extremely Confident, and 1=Not Confident. The overall means for confidence in these topics were very neutral, and in the "uncertain" category. No topic was extremely high or low. The highest mean was 3.90 out of 5 
for the meat science topic of "sanitation." This was followed by wholesale cuts $(M=3.54)$, and retail cuts $(M=3.51)$. The meat science topics which had the lowest mean in confidence were history of meat $(M=2.92)$ and hazard analysis critical control point (HACCP) $(M=2.97)$. This discrepancy in confidence surrounding certain topics could be the result of the FDST 365 Muscle Foods Technology course offered to preservice teachers at West Virginia University. After examining the course syllabus, it was found that topics with higher means were interwoven into the curriculum, while the topics with lower means were not taught. The outlier, however, is HACCP, which was taught in the FDST 365 course, as well as in the laboratory class associated with the course. The lower confidence level in HACCP could be the result of low self-efficacy in teaching a topic that is very specific, and potentially misunderstood by many teachers.

When asked to rank their confidence in teaching different species of meat products. the majority of the West Virginia SBAE teachers were most confident in teaching about pork $(M=$ $2.14, S D=1.62)$, beef $(M=2.16, S D=0.99)$, and poultry $(M=3.84, S D=1.88)$. This could be the result of West Virginia SBAE teachers highlighting this content as they work with students to prepare for the Ham, Bacon, and Egg Show. Another potential factor is the diversity of learning experiences offered through studying pork as opposed to other species; during the curing process, pork is a species that is easily available and provides students the opportunity to see and learn about processing techniques. In addition, cow and calf operations make up $21 \%$ of the agricultural receipts in the state of West Virginia, and poultry production is the state's number one agricultural commodity (Bushel, 2021). Because of this, beef and poultry are species that are also more readily available to teachers across the state. These 3 species were also found to be taught in the Food Science and Technology (FDST) 365 Muscle foods technology course offered to preservice teachers at West Virginia University. 
Respondents were presented with a list of statements to assist in determining their selfefficacy levels in regard to teaching meat science. Overall, the means of these statements were in the uncertain category, but more inclined to agree with the statements. These items utilized a 5point Likert scale, with $5=$ Strongly agree and $1=$ Strongly disagree. The statement with the highest mean (3.76 out of 5) stated, "Given a choice, I would not invite the principal to evaluate my meat science teaching." This can be interpreted as the majority of the teachers disagreed with allowing the principal to evaluate their meat science teaching. This was followed by the statement, "I am typically able to answer students' meat science questions," which had a mean of 3.70 out of 5 . In this item, teachers were still uncertain, but inclined to agree with this statement. The statement with the lowest mean (2.89 out of 5) stated, "Given a choice, I would not invite the principal to evaluate my meat science curriculum." This shows that the majority of the teachers disagreed with this statement and were not opposed to allowing the principal to examine their curriculum. Overall, teachers were efficacious when teaching meat science; however, they were not overly confident to do so. These results confirm the research of Hamilton and Swortzel (2007), who also found that teachers had a higher self-efficacy level when it came to delivering science concepts to their students. These findings also agree with the research of Ulmer et al. (2013), who stated that the Curriculum for Agricultural Science Education (CASE) Institute's professional development had a positive impact on teachers' self-efficacy to teach science.

Respondents were presented with a list of statements to assist in determining their selfefficacy levels in regard to the outcome expectancy of teaching meat science. Outcome expectancy is the level at which teachers expect certain behaviors to produce desirable outcomes. These are things that are out of the control of the teachers, such as student interests, educational goals, cultures, and childhood environments. This question utilized a 5- point Likert scale with 
$5=$ Strongly agree and $1=$ Strongly disagree.

Overall, the majority of the means were lower than the responses to their self-efficacy levels, however, they were found in the lower uncertain category. This suggests that the teachers felt very neutral towards their ability to create changes of certain behaviors through the delivery of meat science but, they were slightly inclined to agree.

The statement with the highest mean (3.97 out of 5) stated, "The inadequacy of a student's meat science background can be overcome by good teaching." The data showed that teachers were mostly in agreement with the statement, meaning teachers agreed that good teaching can help students who do not come from a meat science background. This statement was followed by, "When meat science scores of students improve, it is most often due to their teacher having found a more effective teaching approach" $(M=3.75, S D=0.69)$. Teachers agree that when teachers find a more effective teaching approach, the students' meat science scores improve. The statement with the lowest mean (2.47 out of 5) stated, "The low meat science achievement of some students cannot generally be blamed on their teachers." This can be interpreted as the teachers disagreeing with the statement that "low achievement cannot be blamed on teachers," suggesting that many agree that low achievement of students is at the fault of the teachers.

The statements with the higher means of agreement found that teachers believe that if they provide: good teaching, more effective teaching approaches, effectiveness in curriculum planning, extra attention, and effort, they can impact the scores in meat science courses. These results were also found in the research of J. Desouza, et. al. (2004), R. Hendrix (2019), and M. Tschannen-Moran, et. al., (1998). However, the data also showed that teachers believe that their ability to teach meat science mattered until they were presented with students who had low 
motivation $(M=3.22, S D=0.76)$. In addition, teachers also agreed $(M=3.00, S D=0.79)$ that increased effort in teaching may not help some students' achievement. This can be interpreted as that sometimes, no matter how much effort is put forth you cannot reach all students. These findings confirm the research of M. Tschannen-Moran, et. al., (1998). Tschannen-Moran et. al., (1998) also stated that self efficacy is a construct that deals with both context and subject matter specifics. This means that a teacher may feel more efficacious in the outcome expectancy in certain topics of meat science, or when assisting certain students. This study found that they were not confident in their ability to impact students learning when there was low motivation in the students. The statements with the lower means found that teachers disagree that ineffective teaching is the only reason for low achievement, good meat science teaching abilities cannot help some kids learn, and low achievement cannot be blamed on teachers.

When prompted to select their level of agreement to various barriers of integrating meat science into their curriculum, teachers were found again in the uncertain category, but leaned strongly toward disagreement. This question also utilized a 5-point Likert scale with 5=Strongly agree and $1=$ Strongly disagree. In this context, a barrier is anything that would prevent the teacher from integrating meat science into their curriculum. Although teachers did indicate a few barriers, overall, the teachers did not see all of the provided statements as barriers. Statements that the teachers did consider as barriers to teaching meat science were funding, necessary materials, time, support, lack of experience, and background. Statements that the teachers did not identify as barriers were lack of parent support, administrative support, science teacher support, and student discipline.

The statement with the highest mean (3.47 out of 5) stated, "There is insufficient funding." Teachers agreed that a lack of funding is a barrier in teaching meat science. This 
statement was followed by the statement "I don't have the necessary materials," with a mean of 3.33. Teachers agreed that a lack of necessary materials is a barrier to teaching meat science. The statement with the lowest mean (1.94) stated, "I have tried integrating meat science and it was unsuccessful." Teachers disagreed with this statement. This could be the result of teachers not integrating meat science into the curriculum or could be the result of successful implementation of meat science content. Overall, however, the teachers disagreed that the list of potential barriers presented an obstacle to integrating meat science into their curriculum.

\section{Professional Development}

Respondents were asked what types of professional development would help them to feel more confident in teaching meat science. Meat science professional development had the largest number of respondents (100\%). This was followed by incorporating STEM components into meat science (36.67\%) and STEM professional development (30\%). These results align with the results found in teachers' confidence in teaching meat science topics and in integrating STEM topics. Although the confidence levels for meat science topics were moderately high, West Virginia SBAE teachers are willing to learn more about meat science to become more proficient in their knowledge. In addition, the desire for STEM professional development aligns with the results found in the items about STEM integration. Although the confidence levels for STEM education were moderately high, West Virginia SBAE teachers are willing to learn more about STEM components to become more effective in their teaching strategies.

\section{Conclusions and Implications}

The Perceptions and Instructional Practices used by West Virginian Secondary Agricultural Teachers in Meat Science Education study, found interesting results that gave a better insight of how meat science is being taught, and where professional development is 
needed. One-third of the respondents do teach meat science while one-third do not; a further third participates in HBE shows but does not teach meat science formally. These results show that meat science and the HBE show are a key component of West Virginia SBAE programs. Furthermore, approximately two-thirds of the West Virginia SBAE teachers educate students about meat science, even when slightly over half of the teachers have access to a meat lab. Even when teachers might not teach meat science in a formal unit but participate in the HBE show, they are still teaching meat science. Although the content may not be delivered to every single student, students in the HBE program learn concepts related to meat science.

The project-based nature of the HBE program may bring even more positive learning outcomes; students are focused on working on their project and do not realize the basic meat science skills they are obtaining. However, it is understandable that some teachers hesitate to bring every student into the meat lab during the Ham and Bacon curing process. Students who participate in HBE invest large amounts of money into their product throughout raising and into the butchering stage. This product and show serve as an SAE for all students who participate and is very important for their success in the program. Unfortunately, some students who do not participate in HBE may not see the amount of work and money invested and could accidentally or intentionally ruin a project.

Moreover, it is appalling that two-thirds of the West Virginia SBAE teachers educate students about meat science, even when only a little over half of the teachers have access to a meat lab. Although meat science and HBE is very important to the WV SBAE teachers, it is not the only subject being taught, and it may not be applicable in every community. However, it is evident that meat science education is an important component of West Virginia SBAE programs. 


\section{Research objective One}

The research found that more than half of the respondents have access to a meat lab, and that half of the respondents who teach meat science teach it as a full course. Having access to a meat lab obviously makes it easier to teach meat science, especially and as a full course. It was also found that one-quarter of the teachers deliver meat science as a complete unit plan, and onequarter as an individual lesson in a different unit plan.

When teaching meat science, the most common methods used are demonstration, lecture, and discussion/questioning, and problem solving. This finding aligns with Kolb's experiential learning theory. The concrete experience of Kolb's theory is provided by the demonstration teaching method, which provides a visual presentation of a step-by-step process. This method also utilizes the "I do," "we do," "you do" approach, which allows the student to see the process, try the process with assistance, and then test their learning by doing the process by themselves.. New understandings can then be created from this demonstration, as well as through the lecture, discussion, and questioning process. Problem-solving then allows the students to test their new understandings in a different context, which then cycles back to a new concrete experience.

The West Virginia SBAE teachers mainly teach meat science during the months of November and March which align with the required preparation dates for the HBE show. The research also found that the topics and species that are taught the most in-depth, in descending order, are wholesale cuts, retail cuts, pork, beef, fabrication, sanitation, lamb, and poultry. The high value of each of these topics in the curriculum could be the result of the FDST 365 Muscle Foods Technology course offered to preservice teachers at West Virginia University. After examining the course syllabus, it was found that each of these topics were interwoven into the curriculum. This could also be the result of highlighting critical knowledge used by West Virginia SBAE teachers working with students to prepare for the Ham, Bacon, and Egg shows. 
Another potential factor is the diversity of learning experiences offered through studying pork as opposed to other species; during the curing process, pork is a species that is easily available and provides students the opportunity to see and learn about processing techniques. In addition, cow and calf operations make up $21 \%$ of the agricultural receipts in the state of West Virginia, and poultry production is the state's number one agricultural commodity (Bushel, 2021). Because of this, beef and poultry are other species that are also more readily available to teachers across the state.

In the study, teachers stated that their reason for not teaching meat science is a lack of facilities. Having access to a meat lab makes it easier to teach meat science. The majority of those who teach meat science as a full course (50\%) also presumably have access to a meat lab $(59.50 \%)$. The reality of not having access to a meat lab may prevent teachers from not teaching meat science.

\section{Research Objective Two}

Agriculture teachers are most confident in teaching science and technology as opposed to math and engineering. These results confirm the research of R. Hendrix (2019), who also found that agriculture teachers generally had higher teaching efficacy scores regarding science and technology, and lower teaching efficacy scores regarding engineering and mathematics.

West Virginia SBAE teachers were in the uncertain/neutral category when asked about their perspectives about integrating STEM components into meat science. However, the overall means were trended towards agreement. It can be inferred that overall, the West Virginia SBAE teachers agree that integrating STEM components into meat science courses is beneficial to students in better understanding concepts from other core classes; however, it does take extra effort to prepare on the teacher's part. 
More than half of the respondents who indicated that they teach meat science have already integrated STEM components into their curriculum. It is obvious that the majority of the teachers see the benefit of integrating STEM and have already worked to implement STEM into their curriculum. However, some teachers may not have the time or material to teach STEM components to students, or identify STEM as a technique they are not as efficacious in.

\section{Research Objective Three}

The meat science topics and species West Virginia SBAE teachers are most confident in teaching are sanitation, wholesale and retail cuts, and pork and beef species. This finding aligns with the depth of topics taught, as reported by the teachers in the survey; teachers reported sanitation, wholesale cuts, retail cuts, and pork and beef as the topics they taught in the most depth. This could be the result of the FDST 365 Muscle Foods Technology course offered to preservice teachers at West Virginia University; after examining the course syllabus, it was found that each of these topics were interwoven into the curriculum. This could also be the result of West Virginia SBAE teachers choosing to highlight species-specific knowledge when working with students to prepare for the Ham, Bacon, and Egg shows. Another potential factor is the diversity of learning experiences offered through studying pork as opposed to other species; during the curing process, pork is a species that is easily available and provides students the opportunity to see and learn about processing techniques. In addition, cow and calf operations make up 21\% of the agricultural receipts in the state of West Virginia (Bushel, 2021). Because of this, beef is another species that is more readily available to teachers across the state.

West Virginia SBAE teachers are more uncertain about their efficacy level in teaching meat science; however, they trend slightly towards agreement. Overall, teachers were efficacious when teaching meat science; however, they were not overly confident. These results confirm the 
research of Hamilton and Swortzel, (2007) who also found that teachers had a higher selfefficacy level when it came to delivering science concepts to their students. The majority of teachers are delivering some type of meat science education, and though they are efficacious, are uncertain in that endeavor. Perhaps meat science professional development is needed in order to assist West Virginia SBAE teachers to feel more confident in delivering meat science education. The research of Ulmer et al. (2013) proves that professional development can help in increasing self-efficacy levels. This research states that the CASE Institute's professional development had a positive impact on teachers' self-efficacy to teach science.

West Virginia SBAE teachers reported that they feel less efficacious in the belief they can impact the outcomes of teaching meat science. Overall, the majority of the means were lower than the responses to their self-efficacy levels, however, they were found in the lower uncertain category. This suggests that the teachers felt very neutral towards their ability to create changes of certain behaviors through the delivery of meat science but, they were slightly inclined to agree. The results showed that teachers believe that if they provide: good teaching, more effective teaching approaches, effectiveness in curriculum planning, extra attention, and effort, they can impact the scores in meat science courses. These results were also found in the research of J. Desouza, et. al. (2004), R. Hendrix (2019), and M. Tschannen-Moran, et. al., (1998). The data also showed that teachers think their ability to teach meat science mattered until they were presented with students who had low motivation $(M=3.22, S D=0.76)$. In addition, teachers also agreed $(M=3.00, S D=0.79)$ that increased effort in teaching may not help some students' achievement. This can be interpreted as that sometimes, no matter how much effort is put forth you cannot reach all students. These findings confirm the research of M. Tschannen-Moran, et. al., (1998). Tschannen-Moran et. al., (1998) also stated that self efficacy is a construct that deals 
with both context and subject matter specifics. This means that a teacher may feel more efficacious in outcome expectancy of certain topics related to meat science, or when assisting certain students. Finally, this section of data showed that ineffective teaching was not the only reason for low achievement in some students.

Teachers are also uncertain when presented with barriers related to integrating meat science into their curriculum. Overall, the means of these statements were in the uncertain category, though leaning strongly toward disagreement. Items that the teachers did consider as obstacles to teaching meat science were funding, necessary materials, time, support, and lack of experience and background in the topic. Statements that teachers did not consider as barriers were lack of parent support, administrative support, science teacher support, and student discipline. Although agriculture teachers did indicate a few barriers to teaching meat science, the teachers did not see all of the provided statements as barriers.

\section{Professional Development}

The majority of the West Virginia SBAE teachers indicated that providing meat science professional development would help them to feel more confidence in teaching meat science. These results align with the results found related to confidence in teaching meat science topics and integrating STEM topics. Although the confidence levels for teaching meat science topics were moderately high, there was not a topic listed that was extremely confident. The topic with the highest mean was sanitation $(M=3.90, S D=1.00)$. The West Virginia SBAE teachers are willing to learn more about meat science to become more proficient in their knowledge. In addition, the teachers' desire for STEM professional development aligns with the result found in the STEM integration. Although the confidence levels for STEM education were moderately high, there was not a component listed that was extremely confident. The topic with the highest 
mean was science $(M=4.18, S D=0.65)$. The West Virginia SBAE teachers reported willingness to learn more about STEM components to become more effective in their teaching strategies.

\section{Recommendations for Future Research}

1. This study found that one-third of the teachers indicated that they do not teach meat science formally but do participate in the HBE show. Even without a formal meat science class or unit, participation in the HBE show provides many learning opportunities. There are certain portions of the HBE process that should be highlighted to ensure students understand the STEM concepts they are learning as they work on their project. Furthermore, the HBE show is something that is unique to the state of West Virginia; however, it is a model that many states could potentially replicate. As more people pursue sustainable models of agriculture, including increased interest in growing and preserving their own food, the HBE model could prove beneficial to many other states. in pursuit of a more sustainable agriculture system, and the ability to grow and preserve their own food. As a result, the ham and bacon curing, and smoking process should be documented as an educational opportunity in order to allow other SBAE programs across the nation to benefit from this model. Documentation of the HBE shows should explain their historical significance, provide rationales for educational opportunities within the show, and should explain the procedures and processes for engaging with the show from start to finish.

2. The top five meat-packing states by number of workers are Nebraska, Iowa, Texas, Kansas and Illinois (Stuesse \& Dollar, 2020). This research recommends a comparative study describing the meat science educational practices in these states, based upon the meat science industry found in said states. This study would assist in determining the impact the meat industry 
has on the educational system, and what current practices are being used to teach meat science in schools.

3. This study found that $58.33 \%$ of respondents who teach meat science integrated STEM components into their meat science curriculum. This research recommends a comparative study on the perceptions of teachers and student achievement outcomes comparing teachers who have integrated STEM into meat science with those who have not integrated STEM into meat science curriculum. In many cases, educational innovations such as STEM integration spread through "word of mouth." Word of mouth may provide motivation to the teachers who have not adopted the innovation of STEM education. In addition, hearing others talk about their experiences with STEM education, may provide a sense of security and support to implement a new teaching method. The fastest way to spread the innovation of STEM education may be through the voices of teachers who have implemented it into their program. The purpose of this study would be to determine both the teachers' perspectives and student achievement outcomes of incorporating STEM into their meat science curriculum.

4. This study found that the majority of the West Virginia SBAE teachers indicated that a meat science professional development would increase their level of comfort with teaching meat science. A future study would measure teacher growth and efficacy after implementing professional development. This study would start with a pre-assessment to determine self-efficacy levels of current teachers in incorporating meat science into their curriculum, and to use meat science as a context to incorporate STEM components. This would be a 3-phase professional development opportunity in which participants would first receive professional development on meat science, then STEM education, and finally on integrating STEM into meat science. Teachers would then be assessed for self-efficacy levels directly after 
the professional development, three months after professional development, and six months after professional development. The purpose of this study would be to determine the impact meat science professional development has on self-efficacy levels of current SBAE teachers.

\section{Recommendations for Practice}

1. This research recommends continuing to prepare preservice agricultural education teachers with STEM education training, specifically surrounding how to integrate STEM into agricultural content. It is also very important to provide STEM classes at a university level for students. This will provide them with concrete examples of effective STEM integration to reflect upon when implementing STEM into their own programs. In addition, more emphasis should be placed on incorporating both engineering and math into the agricultural education curriculum, at the preservice level; this study found lower confidence levels in each of these components. The purpose of this recommendation would be to help preservice teachers to be more confident in integrating STEM components into their curriculum.

2. This study found that the majority of the West Virginia SBAE teachers indicated that a meat science professional development would make them more comfortable with teaching meat science. Future professional development for teachers is recommended to meet this need. A future study would measure teacher growth and efficacy after implementing this professional development. This professional development would start with a pre-assessment to gauge the current meat science, and STEM knowledge of teachers. This would help in preparing the adequate amount of content to cater to different experience levels. This would be a 3-phase professional development opportunity where participants would first receive professional development on meat science, then STEM education, and then finally on integrating STEM into meat science. Teachers would then be assessed for self-efficacy levels directly after the 
professional development, three months after professional development, and six months after professional development. The purpose of this professional development provides meat science and STEM integration training for teachers.

3. Provide professional development opportunities to assist teachers in properly processing hams and bacons while also capitalizing on the educational opportunities the Ham Bacon and Egg shows provide for students. This professional development would be available to any teacher wanting to start a Ham Bacon and Egg show, or for teachers who want to hone their meat preservation and trimming skills. In addition, this professional development would provide lessons and curriculum for implementation to allow all students to engage in and understand the Ham Bacon and Egg show process, with the ultimate goal of providing this unique project-based experience to students across the nation and attracting more participants in the Ham Bacon and Egg shows at the local, regional, and state levels. 


\section{References}

Aberle, E. D., \& Forrest, J. C., Gerrard, D. E., Mills, E. W. (2001). Principles of meat science ( $4^{\text {th }}$ ed.). Kendall Hunt Publishing Company. ISBN: 0-78724720-0

Ary, D., Jacobs, L. C., Sorensen, C. K., \& Walker, D. A. (2014). Introduction to Research in Education ( $9^{\text {th }}$ ed.). Wadsworth Cengage Learning. https://rb.gy/t84w7x

Balschweid, M. A., \& Thompson, G. W. (2002). Integrating science in agricultural education: Attitudes of Indiana agricultural science and business teachers. Journal of Agricultural Education, 43(2), 1-10. https://doi.org/10.5032/jae.2002.02001

Barrick, K., \& Hughes, M. (1993). A model for agricultural education in public schools. Journal of Agricultural Education, 34(3), 59-67. https://doi.org/10.5032/jae.1993.03059

Bandura, A. (1986). Social foundations of thought and action: A social cognitive theory. Englewood Cliffs, NJ: Prentice Hall.

Bandura, A. (1989). Human agency in social cognitive theory. American Psychologist, 44(9), 1175-1184. https://doi.org/10.1037/0003-066X.44.9.1175

Bandura, A. (1997). Self-efficacy: The exercise of control. W H Freeman \& Co.

Beerman, D., (2009). ASAS Centennial Paper: A century of pioneers and progress in meat science in the United States leads to new frontiers. Journal of Animal Science, 87(3), 1192-1198. https://doi.org/10.2527/jas.2008-1542

Boone, H. N., Gartin, S. A., Boone, D. A., \& Hughes, J. E. (2006). Modernizing the agricultural education curriculum: An analysis of Agricultural education teachers' attitudes, knowledge, and understanding of biotechnology. Journal of Agricultural Education, 47(1), 78. https://doi.org/10.5032/jae.2006.01078

Brockey, R., (2021, March 27). What is Social Cognitive Theory? Occasional News and Opinions. https://rb.gy/2uhzfw

Bushel. (2021, March 29) West Virginia Ag facts. https://rb.gy/ujqatw

Bybee, R. W. (2013). The case for STEM education: Challenges and opportunities. National Science Teachers Association. https://rb.gy/nvdi45 
Bybee, R. W. (2010). What is STEM education?. Science, 329(5995), 996. https://doi.org/10.1126/science.1194998

Cheek, J. G., Arrington, L. R., Carter, S., \& Randell, R. S. (1994). Relationship of supervised agricultural experience program participation and student achievement in agricultural education. Journal of Agricultural Education, 35(2), 1-5. https://doi.org/10.5032/jae.1994.02001

Clark, A. R. (2013). Effects of Integrating Mathematical Concepts into An Animal Science Curriculum. [Master's thesis, Utah State University]. Digital commons at USU. https://digitalcommons.usu.edu/etd/1950

Clark, S., Parr, B., Peake, J., \& Flanders, F. (2013, February 3-5) Correlation of secondary agricultural education students' science achievement to number of agricultural education courses passed. [Paper presentation]. Southern Region Conference of the American Association for Agricultural education, Orlando, FL, United States. https://rb.gy/bqf5jw

Conroy, C. A., Dailey, A. L., \& Shelley-Tolbert, C. A. (2000). The move to agriscience and its impact on teacher education in agriculture. Journal of Agricultural Education, 41(4), 51-61. https://doi.org/10.5032/jae.2000.04051

Croom, D. B. (2008). The development of the integrated three-component model of agricultural education. Journal of Agricultural Education, 49(1), 110-120. https://doi.org/10.5032/jae.2008.01110

Dalton State. (2021, February 22) The Origin of Social Cognitive Theory: Social Learning Theory. https://libguides.daltonstate.edu/c.php?g=722740\&p=5486076

Desouza, J. M. S., Boone, W. J., \& Yilmaz, O. (2004). A study of science teaching selfefficacy and outcome expectancy beliefs of teachers in India. Science Education, 88(6), 837-854. https://doi.org/10.1002/sce.20001

Dewey, J. (1897). My pedagogic creed. New York and Chicago E.L. Kellogg \& CO. https://rb.gy/hdf0u0

Dewey, J. (1986). Experience and education. The educational forum, 50(3), 241-252. https://doi.org/10.1080/00131728609335764

Dillman, D. A., Smyth, J. D., \& Christian, L. M. (2014) Internet, phone, mail, and mixed-mode surveys: The tailored design method. ( $4^{\text {th }}$ ed.). John Wiley \& sons, Inc., https://rb.gy/gg5ckt 
Dugger, W. E. (2010, December). Evolution of STEM in the United States. [Paper Presentation]. International Conference on Technology Education Research'nda sunulmuş bildiri 6th Biennial, Gold Coast, Queensland, Australia. https://rb.gy/nq0css

Dunbar, B. (2021, January 29). Sputnik: The Dawn of the Space Age. NASA. https://rb.gy/p3waam

Gonzalez, H. B., \& Kuenzi, J. J. (2012). Science, technology, engineering, and mathematics (STEM) education: A primer. Congressional Research Service. https://rb.gy/yox54q

Haynes, J., Robinson, J., Edwards, M., \& Key, J. (2012) Assessing the effect of using science curriculum to improve agriculture students' science scores: A causal comparative study. Journal of Agricultural Education. 53(2), 15-27. https://doi.org/10.5032/jae.2012.02015

Hannafin, M. J., \& Land, S. M. (1997). The foundations and assumptions of technologyenhanced student-centered learning environments. Instructional science, 25(3), 167202. https://rb.gy/glsdgj

Hendrix, R. E., (2019), Agricultural educators' personal characteristics and self-efficacy beliefs regarding STEM education. [Doctoral Dissertation, Mississippi State University]. Mississippi State University: University Libraries: Institutional Repository.https://rb.gy/wbaef7

Hess, A. (2017). West Virginia FFA to host $74^{\text {th }}$ Ham, Bacon, and Egg Sale. AgDaily. https://rb.gy/3ngm5a

Hui, Y., Nip, W., \& Rogers, R. (2001). Meat science and applications. CRC Press. https://rb.gy/p9hkcl

Johnson, D. M. (1996). Science credit for agriculture: Perceived support, preferred implementation methods, and teacher science course work. Journal of Agricultural Education, 37(1), 22-30. https://doi.org/10.5032/jae.1996.01022

Knobloch, N. A. (2003). Is experiential learning authentic? Journal of Agricultural Education, 44(4), 22-34. https://doi.org/10.5032/jae.2003.04022

Knollinger C. (2019) Meet your (Meat) Maker at Ham, Bacon, and Eggs Auction. West Virginia Public Broadcasting. https://rb.gy/jtemh4

Kolb, A. Y., \& Kolb, D. A. (2009). Experiential learning theory: A dynamic, holistic approach to management learning, education and development. In S. Armstrong \& C. Fukami 
The Sage Handbook of Management Learning, Education and Development (1st ed., pp. 42-68) SAGE Publications Inc. ISBN: 978-1-4129-3539-5

Kolb, D. A. (2015). Experiential learning: Experience as the source of learning and development $\left(2^{\text {nd }}\right.$ ed.). Pearson Education Inc. https://rb.gy/umcf2u

Kolb, D. A., Boyatzis, R. E., \& Mainemelis, C. (2001). Experiential learning theory: Previous research and new directions. In R. J. Sternberg, L. Zhang (Eds.), Perspectives on thinking, learning, and cognitive styles, (pp. 227-247), Routledge. https://doi.org/10.4324/9781410605986-9

Levesque, K., Wun, J., \& Green, C. (2010). Science Achievement and Occupational Career/Technical Education Courses Taking in High School: The Class of 2005. National Center for Education Statistics. https://rb.gy/6duvut

Luszczynska, A., \& Schwarzer, R. (2005). Social cognitive theory. Predicting Health Behaviour, 2, 127-169. https://rb.gy/xtkqdj

Melodia, A., \& Small, T. (2002). Integrating math and science into agriculture. Agricultural Education Magazine. 75(3), 18-19. https://rb.gy/55f764

Moore, G. (2017) The Smith-Hughes Act: The Road to It and What It Accomplished. Techniques Magazine, 92(2), 17-21. https://rb.gy/zbidil

Moore, G. E. (2020, March 5). The West Virginia FFA Ham, Bacon, and Egg Show and Sale. National Association of Agricultural Educators: Friday Footnotes. https://rb.gy/xdnwaj

Myers, B. E., \& Thompson, G. W. (2009). Integrating academics into agriculture programs: a delphi study to determine perceptions of the national agriscience teacher ambassador academy participants. Journal of Agricultural Education, 50(2), 77-88. https://doi.org/10.5032/jae.2009.02075

Myers, B. E., \& Washburn, S. G. (2008). Integrating science in the agriculture curriculum: agriculture teacher perceptions of the opportunities, barriers, and impact on student enrollment. Journal of Agricultural Education, 49(2), 27-37. https://doi.org/10.5032/jae.2008.02027

National FFA Organization. (2020, October 8). About FFA. https://www.ffa.org/about/

National FFA Organization. (2020, October 17). FFA history: About FFA. https://www.ffa.org/ffa-history/ 
National FFA Organization (2021, March 26) Agricultural Education: About FFA. https://www.ffa.org/agricultural-education/

Riggs, I. M., \& Enochs, L. G. (1989). Toward the development of an elementary teacher's science teaching efficacy belief instrument. [Paper presentation] National Association for Research in Science Teaching, San Francisco, CA, United States. https://rb.gy/sy7kel

Roberts, T. G. (2011). What is experiential learning? The Agricultural Education Magazine, 83(4), 4. https://rb.gy/yipleg

Parr, B. A., Edwards, M. C., \& Leising, J. G. (2006). Effects of a math-enhanced curriculum and instructional approach on the mathematics achievement of agricultural power and technology students: An experimental study. Journal of Agricultural Education, 47(3), 81-93. https://doi.org/10.5032/jae.2006.03081

Parr, B., Edwards, M. C., \& Leising, J. G. (2009). Selected effects of a curriculum integration intervention on the mathematics performance of secondary students enrolled in an agricultural power and technology course: An experimental study. Journal of Agricultural Education, 50(1), 57-69. https://doi.org/10.5032/jae.2009.01057

Porter, E. (2014). The current status of meat processing facilities in agricultural education programs in West Virginia. [Graduate Thesis, West Virginia University]. The Research Repository at WVU. https://doi.org/10.33915/etd.614

Ricketts, J., Duncan, D., \& Peake, J. (2006) Science achievement of high school students in complete programs of Agriscience education. Journal of Agricultural Education. 47(2), 48-55. https://doi.org/10.5032/jae.2006.02048

Sanders, M. E. (2008). Stem, stem education, stemmania. The Technology Teacher. December/January 2009, (p.20-26). http://hdl.handle.net/10919/51616

Scales, J., Terry Jr, R., \& Torres, R. M. (2009). Are teachers ready to integrate science concepts into secondary agriculture programs? Journal of Agricultural Education, 50(2), 102-113. https://doi.org/10.5032/jae.2009.02100

Shinn, G. C., Briers, G. E., Christiansen, J. E., Harlin, J. F., Lindner, J. R., Murphy, T. H., \& Lawver, D. E. (2003). Improving student achievement in mathematics: An important role for secondary agricultural education in the 21 st century. [Unpublished Manuscript] Texas A\&M University. https://rb.gy/jlxhhh 
Shoulders, C., \& Myers, B. (2011) Teachers' use of agricultural laboratories in secondary agricultural education. Journal of Agricultural Education, 53(2), 124-138. https://doi.org/10.5032/jae.2012.02124

ShoWorks Auction. (2021, March 18). WV FFA State HBE Show/Sale. https://rb.gy/nylbs6

Smith, K., \& Rayfield, J. (2016). An early historical examination of the educational intent of supervised agricultural experiences (SAES) and project-based learning in agricultural education. Journal of Agricultural Education, 57(2), 146-160. https://doi.org/10.5032/jae.2016.02146

Smith, K., \& Rayfield, J. (2017). A quasi-experimental examination: cognitive sequencing of instruction using experiential learning theory for stem concepts in agricultural education. Journal of Agricultural Education, 58(4), 175-191. https://doi.org/10.5032/jae.2017.04175

Smith, K., Rayfield, J., \& McKim, B. (2015). Effective practices in stem integration: describing teacher perceptions and instructional method use. Journal of Agricultural Education, 56(4), 183-203. https://doi.org/10.5032/jae.2015.04183

Stelar: Stem Learning and Research Center. (2020). Instruments: Science Teaching Efficacy Belief Instrument (STEBI). https://rb.gy/k199ct

Stone III, J. R. (2011, May). Delivering STEM education through career and technical education schools and programs. National Research Council. https://rb.gy/rcd8de

Stuesse, A., \& Dollar, N. (2020, September 24). Who are America's meat and poultry workers? Economic Policy Institute: Working Economics Blog. https://rb.gy/zahcf5

Swafford, M. (2018). The state of the profession: STEM in agricultural education. Journal of Agricultural Education, 59(4), 315-333. https://doi.org/10.5032/jae.2018.04315

Swatzell, K. E., \& Jennings, P. R. (2007). Descriptive research: The nuts and bolts. Journal of the American Academy of PAs, 20(7). https://rb.gy/sflqou

The Market Bulletin, (2019), $76^{\text {th }}$ Annual Ham, Bacon and Egg Show. Department of Agriculture. 103(4), 5 https://rb.gy/0rs7zj

Thompson, G. W., \& Balschweid, M. M. (1999). Attitudes of Oregon agricultural science and technology teachers toward integrating science. Journal of Agricultural Education, 40(3), 21-29. https://doi.org/10.5032/jae.1999.03021

True, A. C. (1929). A history of agricultural education in the United States, 1785-1925 (No. 36). US Government Printing Office. https://rb.gy/kruwc6 
Tschannen-Moran, M., Hoy, A. W., \& Hoy, W. K. (1998). Teacher efficacy: Its meaning and measure. Review of Educational Research, 68(2), 202-248.

https://doi.org/10.3102/00346543068002202

Ulmer, J. D., Velez, J. J., Lambert, M. D., Thompson, G. W., Burris, S., \& Witt, P. A. (2013). Exploring science teaching efficacy of CASE curriculum teachers: A post-then-pre assessment. Journal of Agricultural Education, 54(4), 121-133. https://rb.gy/jidjpj

Uricchio, C., Moore, G., Coley, M. (2013). Corn clubs: Building the foundation for agricultural and extension education. Journal of Agricultural Education, 54(3), 224 - 237.

https://doi.org/10.5032/jae.2013.03224

Warnick, B. K., Thompson, G. W., \& Gummer, E. S. (2004). Perceptions of science teachers regarding the integration of science into the agricultural education curriculum. Journal of Agricultural Education, 45(1), 62-73. https://doi.org/10.5032/jae.2004.01062

Wooten, K., Rayfield, J., \& Moore, L. L. (2013). Identifying STEM Concepts Associated with Junior Livestock Projects. Journal of Agricultural Education, 54(4), 31-44.

https://doi.org/10.5032/jae.2013.04031 


\section{APPENDIX A: Cover Letter}

January 26,2021

Dear West Virginia, Agricultural teachers,

As a current Agricultural Educator, you are key in understanding how meat science is being taught in public schools throughout WV. Meat science is defined as the study of the science of production, processing and the preservation of meats. Research shows that incorporating science, technology, engineering, and mathematics (STEM) components into secondary Agricultural Education classrooms is beneficial to the students' learning and understanding. West Virginia is known for the meat processing facilities and learning activities in their public schools. However, little is known about how the content is taught or if agriculture teachers include STEM components into their Meat Science curriculum.

I am Kindra Carr, a graduate student in Agricultural and Extension Education; and under the direction of my advisor, Dr. Jessica M. Blythe, we are conducting research to explore and document the teaching methods used by West Virginia Agriculture teachers with their meat science curriculum. The results will be used to prepare a thesis to partially fulfill the requirements for a Master of Science degree in Agricultural and Extension Education.

We are contacting all West Virginia secondary agricultural teachers for this study. This survey includes questions intended to assess (a) How meat science is being taught (b) Self Efficacy levels in regard to STEM education and meat science, and (c). your perspectives on using meat science as a context to incorporate STEM components. This survey will take approximately 15 to 20 minutes. Please take a few moments and share your opinions with us.

The Institutional Review Board (IRB) at West Virginia University has acknowledged this study. If you have any questions or concerns about completing the questionnaire or about being in this study, you may contact me at kwcarr@mix.wvu.edu or my advisor Dr. Jessica Blythe at jmblythe@mail.wvu.edu. Thank you in advance for your assistance with this research effort. We sincerely appreciate your participation.

To begin this survey hit the "continue" button below, and after completing the survey, click the "submit button" no later than February 12th, 2021.

Sincerely,

Kindra Carr

WVU Masters Student 


\section{APPENDIX B: Initial Survey Invitation}

January 26, 2021

Good Evening West Virginia Agriculture Teachers,

As a current Agricultural Educator, you have been chosen to participate in a research study that will determine how meat science is being taught in public schools throughout West Virginia. West Virginia is known for its meat processing facilities and learning activities in public schools.

This survey includes questions intended to assess (a) How meat science is being taught (b) Self Efficacy levels in regard to STEM education and meat science, and (c) your perspectives on using meat science as a context to incorporate STEM components.

This survey is completely voluntary and will take approximately 15 - 20 to complete. The Institutional Review Board (IRB) at West Virginia University has acknowledged this study. If you have any questions or concerns about completing the questionnaire or about being in this study, you may contact me at kwcarr@mix.wvu.edu or my advisor Dr. Jessica Blythe at jmblythe@mail.wvu.edu. Please click the highlighted link below to access the study no later than February 12th. Thank you in advance for your assistance with this research effort. We sincerely appreciate your participation.

Follow this link to the survey:

https://wvu.qualtrics.com/jfe/form/SV_4PIrBkYavOFHzYF

or copy and paste the url Below into your internet browser:

https://wvu.qualtrics.com/jfe/form/SV_4PIrBkYavOFHzYF

Sincerely,

Kindra Carr

Masters Student 


\section{APPENDIX C: Follow-Up Emails}

Follow up Email \#1

February 2, 2021

Dear WV Agricultural Education Teachers:

Last week we sent an email asking for your participation in the study exploring a) If, and how meat science is being taught, (b) Self Efficacy levels in regard to STEM education and meat science, and (c) your perspectives on using meat science as a context to incorporate STEM components.

This study is very important, and your input is vital to its success. This study closes $\mathbf{2 / 2 3 / 2 0 2 1}$. The goal of this study is to gain more information on if, and how meat science is being taught and the self-efficacy of those who do teach it.

\section{Follow this link to take the survey:}

\section{https://wvu.qualtrics.com/jfe/form/SV_4PIrBkYavOFHzYF}

\section{Or copy and paste the url Below into your internet browser:}

https://wvu.qualtrics.com/jfe/form/SV_4PIrBkYavOFHzYF

The results will remain confidential and will not be able to identify a specific individual. Please complete the survey to ensure success of this study. The Institutional Review Board (IRB) at West Virginia University has acknowledged this study. If you have any questions or concerns about completing the questionnaire or about being in this study, you may contact me at kwcarr@mix.wvu.edu.

If you have already participated in this survey, please disregard this email.

Sincerely,

Kindra Carr

Masters Student 
Follow-Up Email \# 2

February 8, 2021

Dear West Virginia Agriculture teachers:

Recently we sent an email asking for your participation in a study about meat science in West Virginia, even if you do not currently teach the subject. We are still interested in discovering confidence levels and barriers in regard to implementation of meat science. This study will be exploring a) How meat science is being taught (b) Self Efficacy levels in regard to STEM education and meat science, and (c) your perspectives on using meat science as a context to incorporate STEM components. Thank you to those who have completed the survey. To those individuals that have not, there is still time.

Follow this link to the Survey:

https://wvu.qualtrics.com/jfe/form/SV_4PIrBkYavOFHzYF

Or copy and paste the URL below into your internet browser:

https://wvu.qualtrics.com/jfe/form/SV_4PIrBkYavOFHzYF

This study is very important, and your input is vital to its success. The study closes $02 / 23 / 21$. The results will remain confidential and will not be able to identify a specific individual. The results will be used to help understand the current status of meat science education in WV, and to determine what types of professional development will be practical to WV agriculture teachers.

Please complete the survey to ensure success of this study. The Institutional Review Board (IRB) at West Virginia University has acknowledged this study. If you have any questions or concerns about completing the questionnaire or about being in this study, you may contact me at kwcarr@mix.wvu.edu.

Sincerely,

Kindra Carr

Masters Student 
Follow Up Email \#3

February 15, 2021

Dear West Virginia Agricultural teachers,

A few weeks ago, we contacted you asking for your help in exploring how meat science is being taught in WV public schools. We need your help to ensure that the results are precise as possible

This study is very important, and your input is vital to its success. The study closes 02/23/21. This study will be exploring a) How meat science is being taught (b) Self Efficacy levels in regard to STEM education and meat science, and (c) your perspectives on using meat science as a context to incorporate STEM components.

Follow this link to the Survey:

https://wvu.qualtrics.com/jfe/form/SV 4PIrBkYavOFHzYF

Or copy and paste the URL below into your internet browser:

https://wvu.qualtrics.com/jfe/form/SV 4PIrBkYavOFHzYF

The results will remain confidential and will not be able to identify a specific individual. The Institutional Review Board (IRB) at West Virginia University has acknowledged this study. The results will be used to help understand the current status of meat science education in $\mathrm{WV}$, and what types of professional development could be practical to WV agriculture teachers. Thank you for considering our request during this busy time of year.

If you have already taken this survey, please disregard this email.

Sincerely,

Kindra Carr

Masters Student 


\section{APPENDIX D: Survey Questions}

Q53 Please select the category which best describes the current meat science teaching practices in your program.

I do teach meat science

I do not teach any meat science

I do not teach meat science formally in any of my classes, but my program participates in the Ham, Bacon and Egg (HBE) show.

Other (Please Specify)

Q45 A meat lab is a learning station in a high school agricultural program, where students learn how to properly process animal carcasses. Most generally they include a freezer, cooler, a work station, and other important processing equipment. Does your program have access to a meat lab?

Yes

No 
Q47 Please select the equipment you have in your meat lab. Please select all that apply.

\section{Band saw}

Breaking knife

Breaking Saw

Boning knife

Freezer

Grinder

Hand Saw

Hanging System

Label Maker

Meat Tenderizer

Mixer

Patty Maker

Personal Protective Equipment 
Processing tables

Refrigerator

Scale

Slicer

Smoker

Vacuum Packer

Other (Please Specify) 
Q46 Please answer the following question, even if you do not currently teach meat science.

Please mark the level of confidence in knowledge you have about teaching each topic on the left column.

\begin{tabular}{|c|c|c|c|c|c|c|}
\hline & $\begin{array}{c}\text { Extremely } \\
\text { Knowledge } \\
\text { able (1) }\end{array}$ & $\begin{array}{c}\text { Very } \\
\text { knowledge } \\
\text { able (2) }\end{array}$ & $\begin{array}{c}\text { Moderately } \\
\text { knowledge } \\
\text { able (3) }\end{array}$ & $\begin{array}{c}\text { Slightly } \\
\text { knowledge } \\
\text { able (4) }\end{array}$ & $\begin{array}{c}\text { Not } \\
\text { knowledg } \\
\text { able (6) }\end{array}$ & $\begin{array}{l}\text { N/A } \\
(5)\end{array}$ \\
\hline Byproducts & $\bigcirc$ & 0 & $\bigcirc$ & 0 & 0 & \\
\hline $\begin{array}{l}\text { Curing and } \\
\text { Smoking }\end{array}$ & $\bigcirc$ & $\bigcirc$ & $\bigcirc$ & 0 & $\bigcirc$ & \\
\hline Fabrication & ○ & $\bigcirc$ & $\bigcirc$ & 0 & $\bigcirc$ & \\
\hline $\begin{array}{l}\text { Fresh Meat } \\
\text { Properties }\end{array}$ & $\bigcirc$ & 0 & $\bigcirc$ & 0 & 0 & \\
\hline $\begin{array}{l}\text { Food Group / } \\
\text { Nutrition }\end{array}$ & $\bigcirc$ & 0 & 0 & $\bigcirc$ & 0 & \\
\hline $\begin{array}{c}\text { Hazard } \\
\text { Analysis } \\
\text { Critical } \\
\text { Control Point }\end{array}$ & $\bigcirc$ & 0 & $\bigcirc$ & 0 & 0 & \\
\hline
\end{tabular}




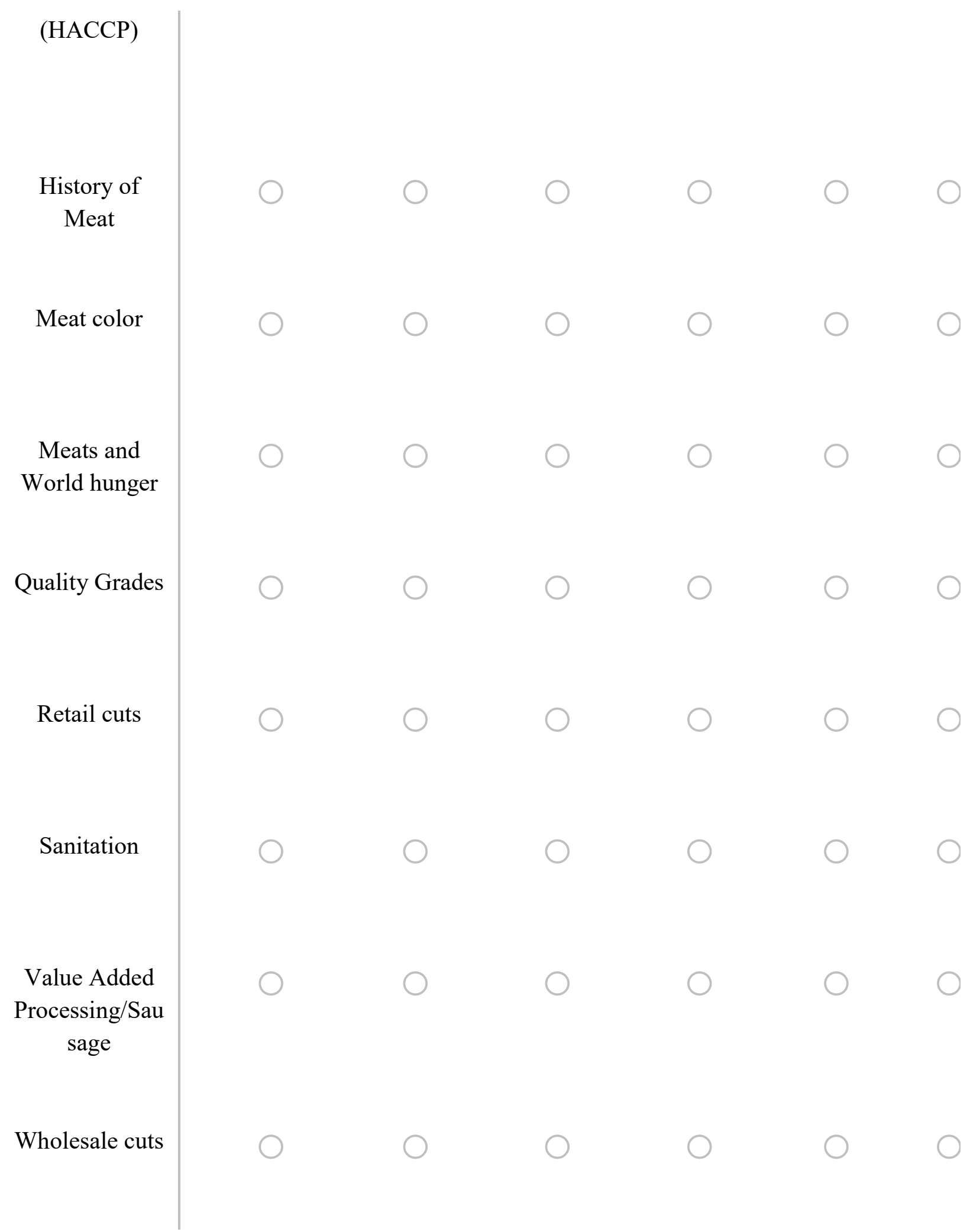


Yield Grades

Q67 Please rank the species of meat products based off your confidence in teaching them, from most confident (1.) to least confident (8). Rank them by using your cursor to drag the species to the proper placing.

Beef

Fish

Goats

Lamb

Pork

Poultry

Veal

Venison

Q52 Select the answer that best describes your confidence in your ability to teach 


\begin{tabular}{|c|c|c|c|c|c|}
\hline & $\begin{array}{l}\text { Completely } \\
\text { Confident (9) }\end{array}$ & $\begin{array}{c}\text { Fairly } \\
\text { Confident } \\
(10)\end{array}$ & $\begin{array}{c}\text { Somewhat } \\
\text { Confident } \\
\text { (11) }\end{array}$ & $\begin{array}{c}\text { Slightly } \\
\text { Confident } \\
\text { (12) }\end{array}$ & $\begin{array}{c}\text { Not } \\
\text { Confident at } \\
\text { all (13) }\end{array}$ \\
\hline Agriculture & & & & & \\
\hline $\begin{array}{c}\text { Engineering } \\
\text { Concepts }\end{array}$ & & & & & \\
\hline Food Science & & & & & \\
\hline $\begin{array}{l}\text { Grading } \\
\text { Criteria }\end{array}$ & & & & & \\
\hline $\begin{array}{l}\text { Inspection } \\
\text { Criteria }\end{array}$ & & & & & \\
\hline Math Skills & & & & & \\
\hline $\begin{array}{l}\text { Science } \\
\text { Skills }\end{array}$ & & & & & \\
\hline $\begin{array}{c}\text { Species } \\
\text { Knowledge }\end{array}$ & & & & & \\
\hline $\begin{array}{c}\text { Technology } \\
\text { Use }\end{array}$ & & & & & \\
\hline
\end{tabular}




\begin{tabular}{c|} 
Whole Sale \\
Cuts
\end{tabular}

\title{
I do not teach Meat science but participate in Ham Bacon and Egg show.
}

Q21 Please explain why you do not to teach meat science? (Select all that apply)

Administration Decision

\author{
Lack of Facilities
}

My Decision

School and Community Expectations

Situational Decision

Other (Please Specify) 
Q22 Do you see the Ham Bacon Egg (HBE) process as an educational opportunity for students?

Yes

No

It depends on how it is incorporated into the agricultural education program.

This question was only displayed if Yes was selected for the previous questions

Q55 What do you think students learn through the HBE Process?

Q48 Please rank the outcomes students obtain from the HBE process from most beneficial (1.) to least beneficial (5.). Do this by using your cursor to drag the outcome to the proper placing.

Proper nutrition and Animal Care 
Marketing Products/making connections with buyers

Animal selection based on certain traits

Learning to preserve meat

Learning chemical changes in preserving process

Pork Fabrication Knowledge

Q54 Please explain why you placed the outcomes in that order, and list any other important outcomes not listed that you have experienced. 


\section{Do Not Teach Meat Science}

Q4 Please explain why you do not to teach meat science? (Select all that apply)

$\square$ Administration Decision

Lack of Facilities

$\square$ My Decision

$\square$ School and Community Expectations

Situational Decision

Other (Please Specify)

\section{Do Teach Meat Science}

Q43 How do you teach meat science?

I teach it as an individual lesson in a different unit plan

I teach a complete unit plan

I teach it as a full course 
Q12 Please check each of the methods you have used to teach meat science. Select all that apply.

$\square$ Brainstorming

Case Studies

Computer aided instruction

Cooperative Learning

Demonstration

Discussion/Questioning

Experiments 


\section{Field trips}

Guest Speakers

Independent Study

Instructional Posters

Lecture

Problem solving

Supervised study

Q14 Please mark how in depth you teach the list of topics on the left hand column, with 1 being very in depth, and 5 none at all.

\begin{tabular}{c|cccc} 
& $2(2)$ & $3(3)$ & $4(4)$ & 5 (None at \\
all) (5)
\end{tabular}




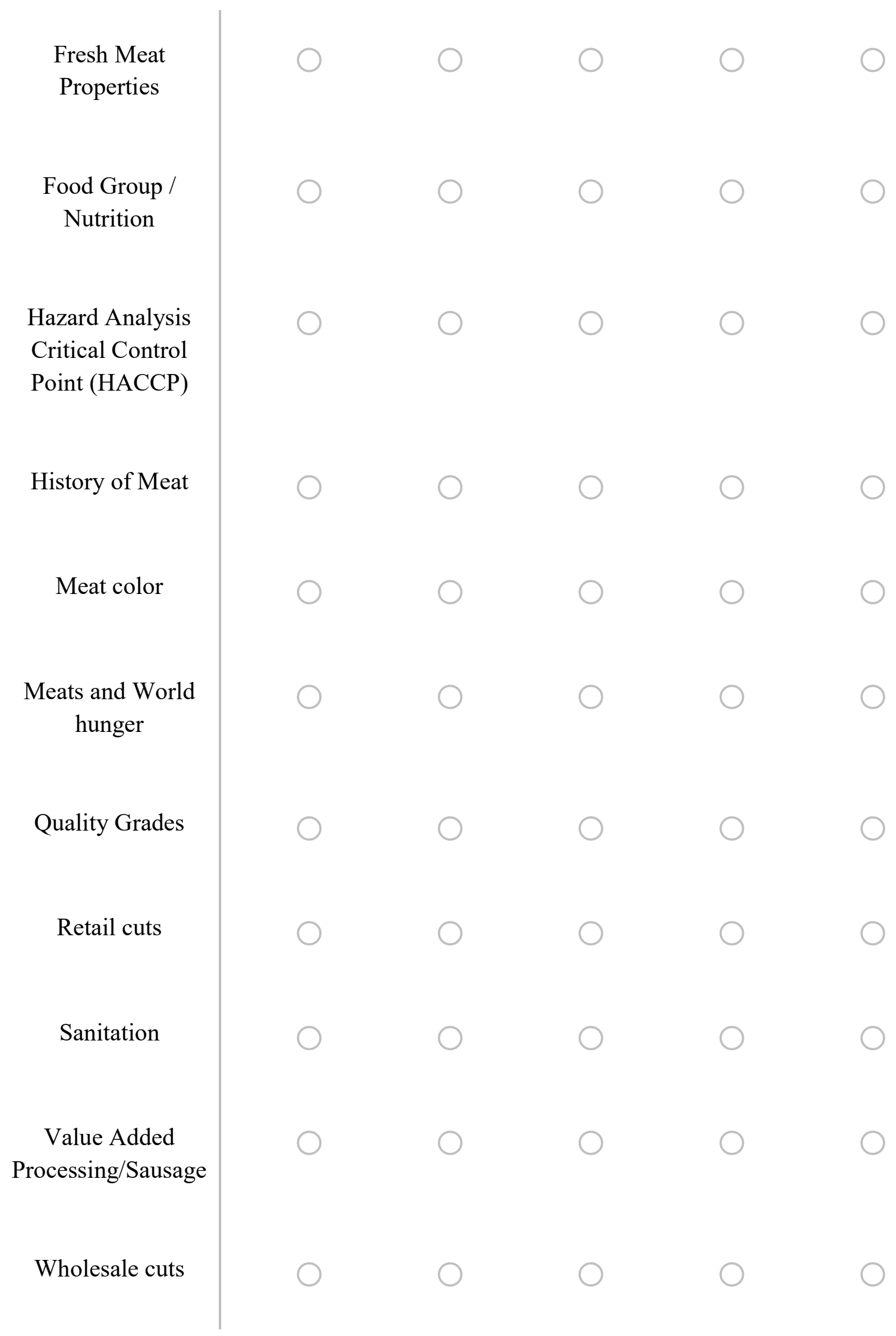




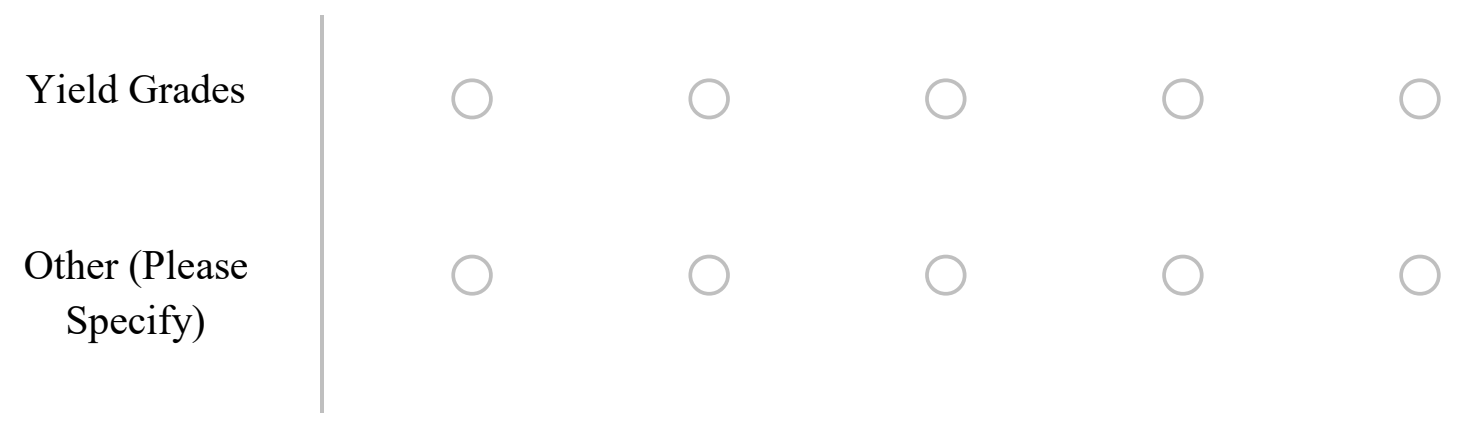

Q68 Please mark how in depth you teach the list of species on the left hand column, with 1 being very in depth, and 5 none at all.

\begin{tabular}{|c|c|c|c|c|c|}
\hline & $\begin{array}{l}1 \text { (Very in } \\
\text { depth) (1) }\end{array}$ & $2(2)$ & $3(3)$ & $4(4)$ & $\begin{array}{c}5 \text { (None at } \\
\text { all) (5) }\end{array}$ \\
\hline Beef & 0 & & & & \\
\hline Fish & $\bigcirc$ & & & & \\
\hline Goats & & & & & \\
\hline Lamb & & & & & \\
\hline Pork & $\bigcirc$ & ( & & & \\
\hline
\end{tabular}




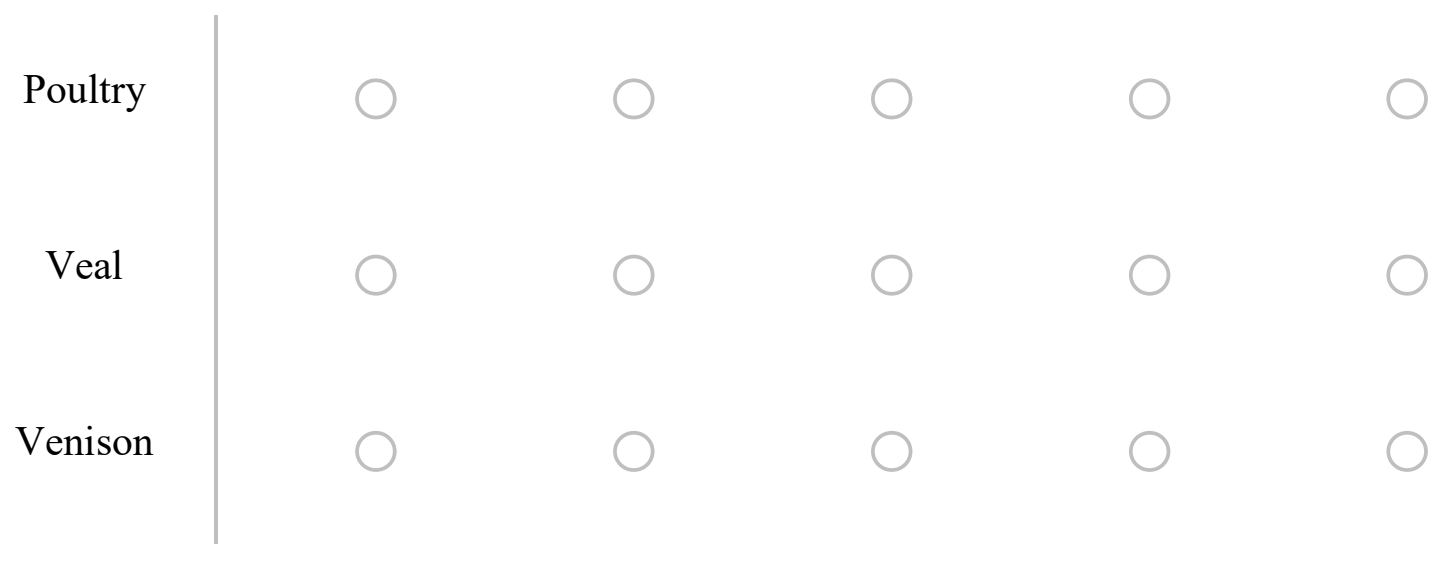

Q17 Please indicate the average number of days that you teach a full meat science lesson in each month.

August:

September:

October:

November:

December:

January:

February:

March:

April:

May: 
Total:

\section{Perceptions of Integrating STEM into Meat Science}

Q70 Please indicate the degree to which you agree or disagree with each statement below.

\begin{tabular}{c|cccc} 
& $\begin{array}{c}\text { Strongly } \\
\text { agree }\end{array}$ & $\begin{array}{c}\text { Strongly } \\
\text { disagree }\end{array}$ \\
\hline $\begin{array}{c}\text { Students learn } \\
\text { more about } \\
\text { meat science } \\
\text { when STEM } \\
\text { components } \\
\text { are an integral } \\
\text { part of their } \\
\text { instruction. }\end{array}$ & \\
Students are \\
more
\end{tabular}




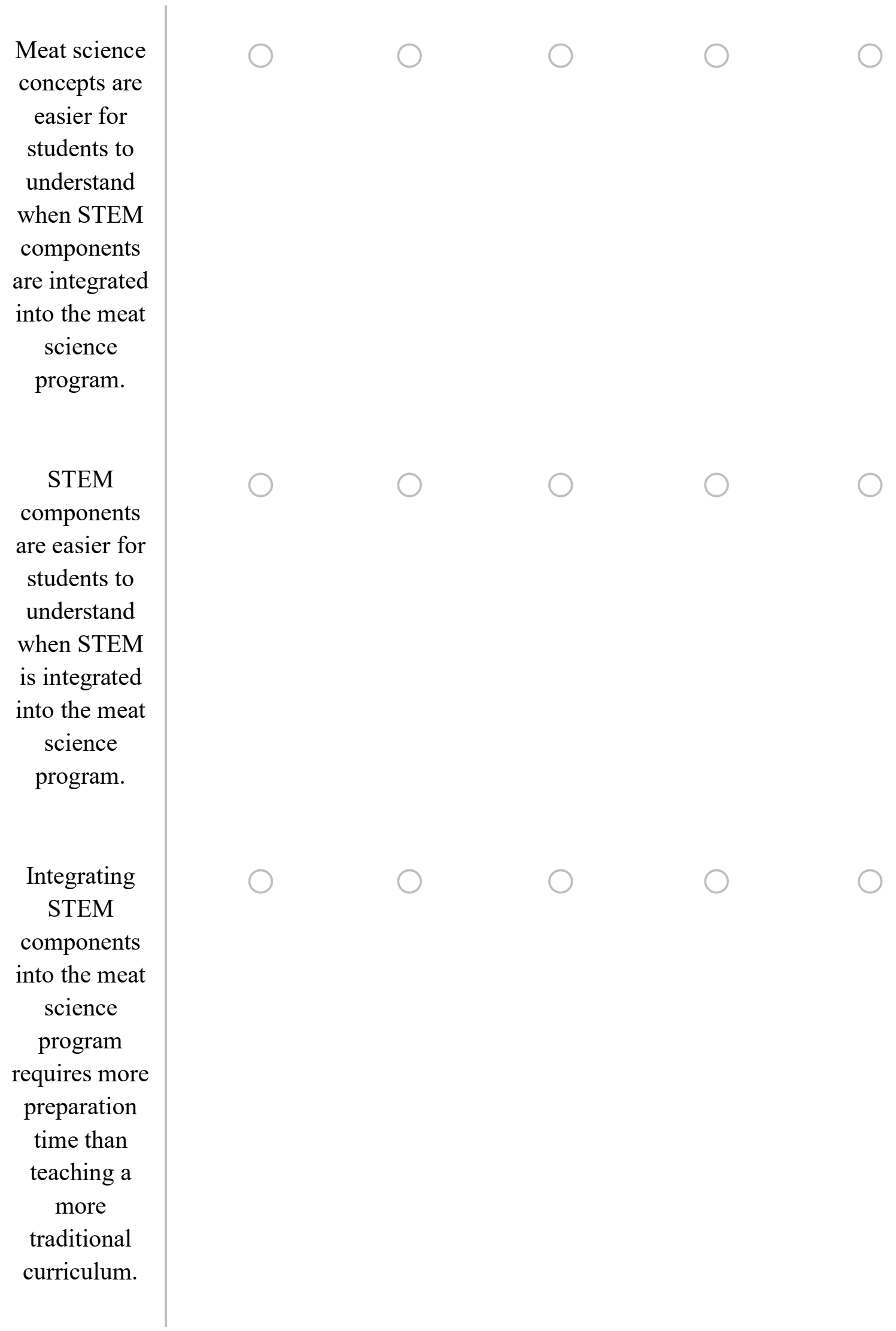


Less effort is required to integrate STEM in advanced courses as compared to introductory courses.

Integrating STEM components into meat science classes increases the ability to teach students to solve problems.

Integrating

STEM components into the meat science curriculum more effectively meets the needs of special population students (i.e. learning 


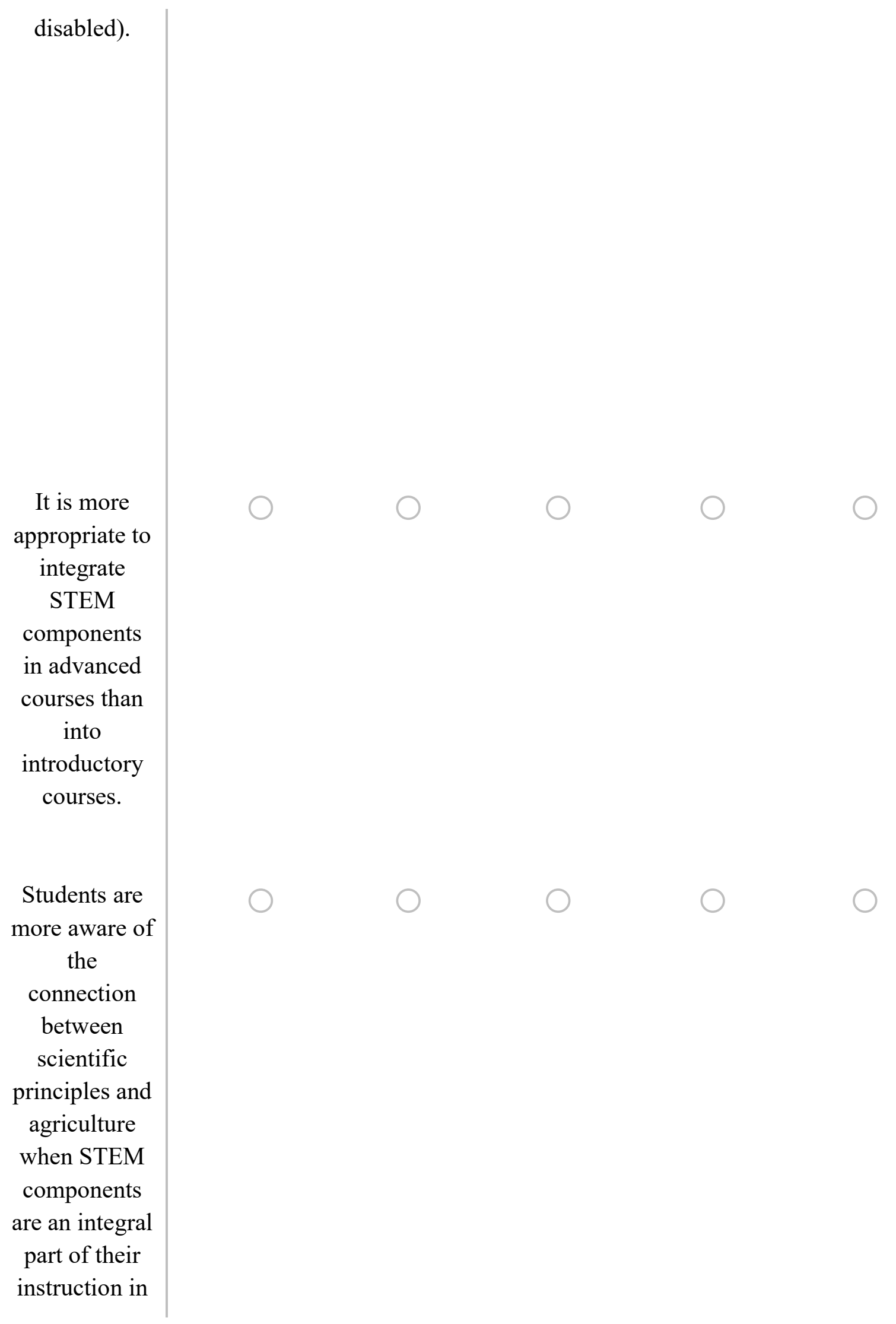




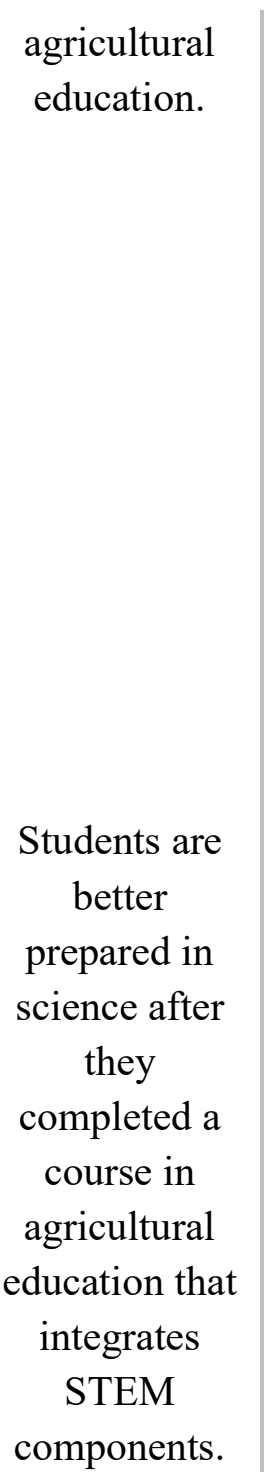


Q72 Have you integrated STEM components into your meat science instruction?
Yes
No

This question was only displayed if Yes was selected for the previous questions

Q73 How have you integrated STEM components into your classroom 
Q75 Please indicate the degree to which you agree or disagree with each statement below.

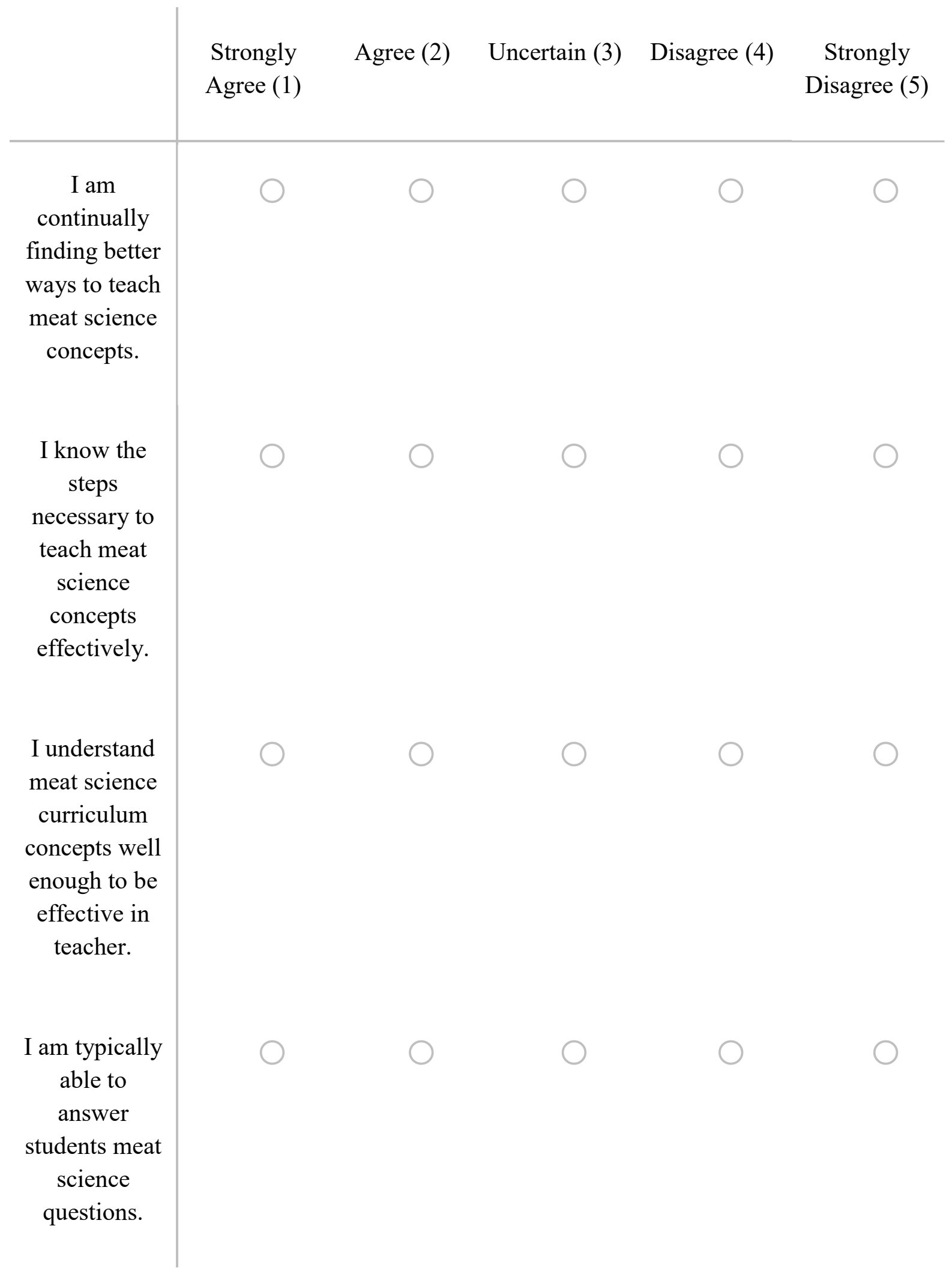




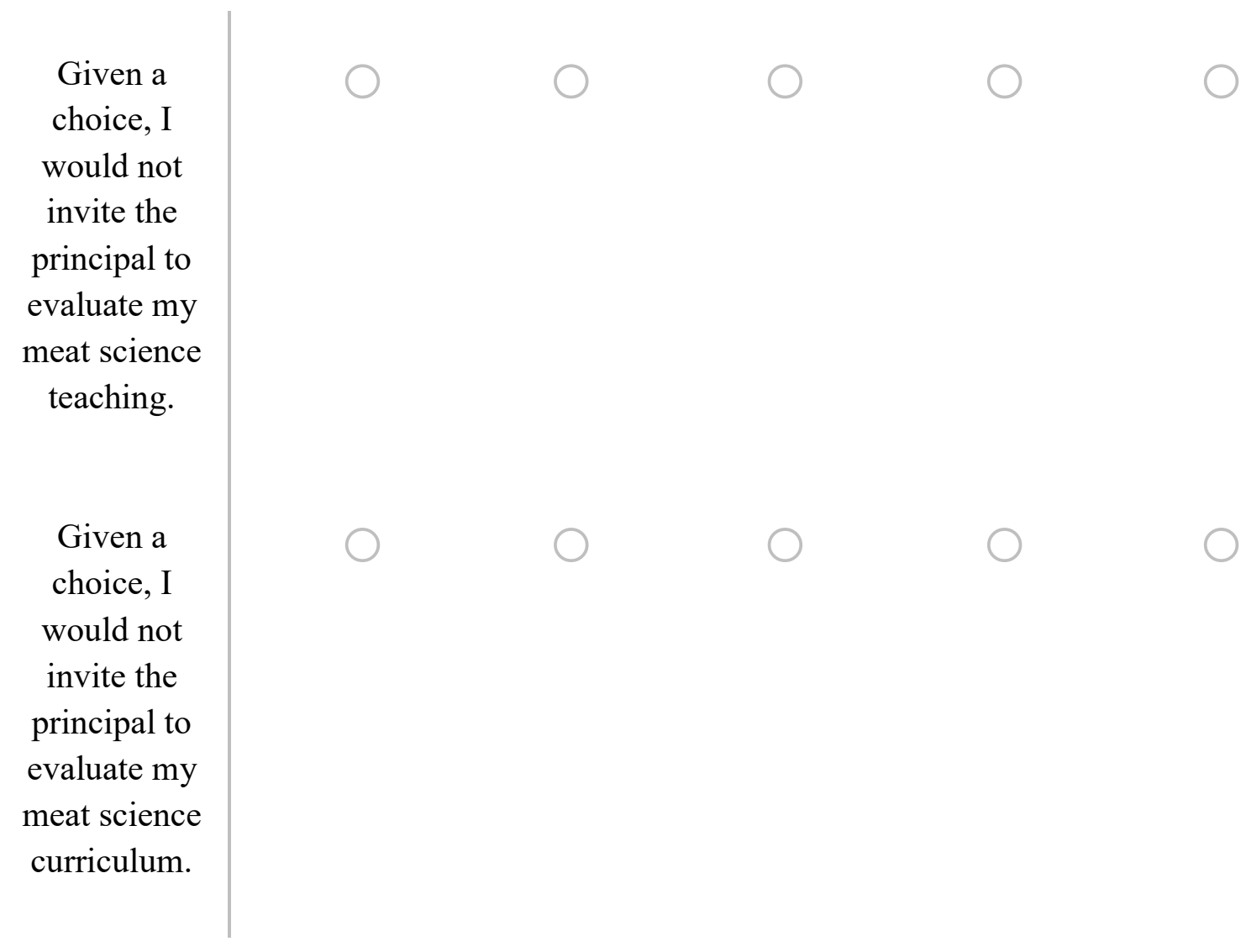

\section{Self-efficacy in the outcomes of teaching meat science}

Q69 Please indicate the degree to which you agree or disagree with each statement below.

\begin{tabular}{ccccc} 
Strongly & Agree (7) & Uncertain & Disagree (9) & $\begin{array}{c}\text { Strongly } \\
\text { disagree }\end{array}$ \\
agree (6) & & $(8)$ & $(10)$ \\
& & & \\
\hline
\end{tabular}


When a student does better than usual on meat science exams, it is often because the teacher exerted a little extra effort.

When meat science scores of students improve, it is most often due to their teacher having found a more effective teaching approach.

If students are underachieving in a meat science course, it is most likely due to ineffective teaching.

The inadequacy of a student's meat science background can be overcome by good 


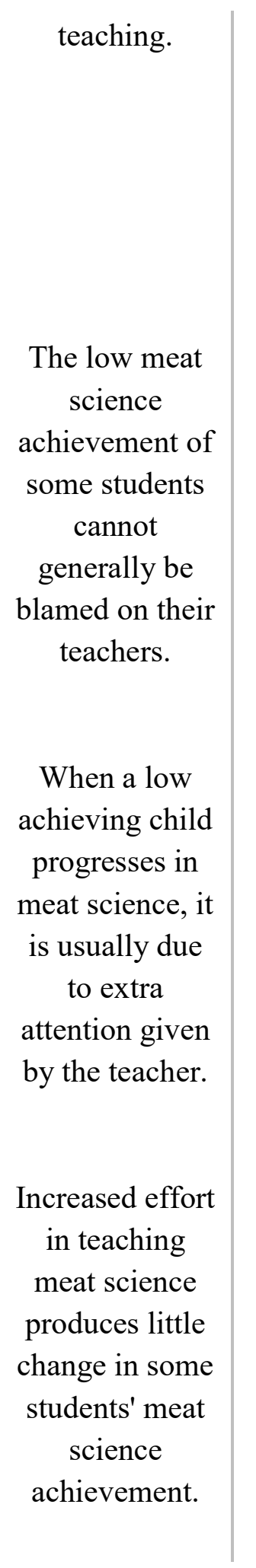




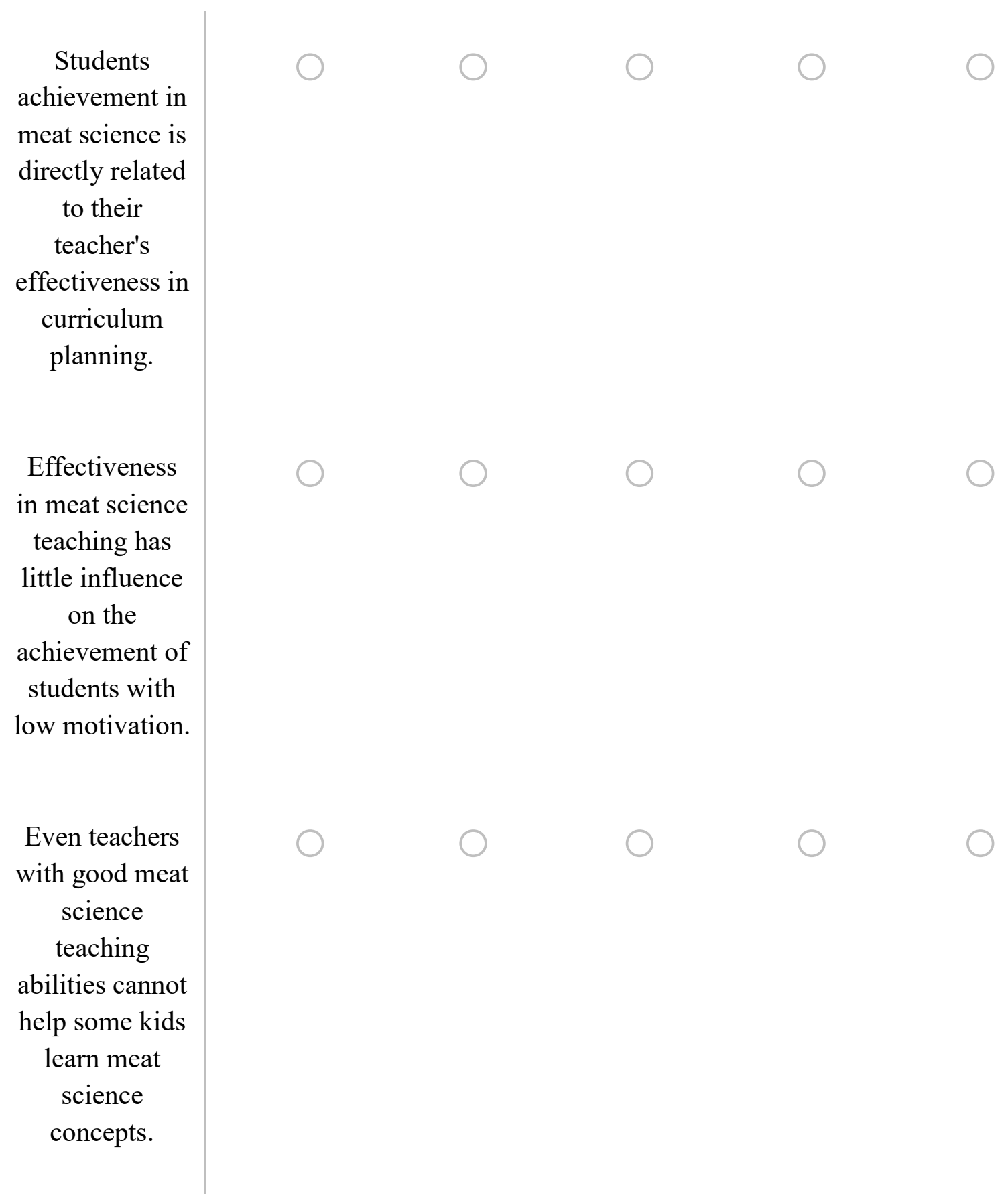

\section{Barriers to integrating meat science into curriculum}

Q65 Using the scale below, please indicate the degree to which you agree or disagree with the following items as barriers to integrating meat science curriculum. Please answer each 
question.

\begin{tabular}{|c|c|c|c|c|c|}
\hline & $\begin{array}{l}\text { Strongly } \\
\text { Agree (1) }\end{array}$ & Agree (2) & $\begin{array}{l}\text { Uncertain } \\
\text { (3) }\end{array}$ & Disagree (4) & $\begin{array}{c}\text { Strongly } \\
\text { Disagree (7) }\end{array}$ \\
\hline $\begin{array}{l}\text { I have a lack of } \\
\text { experience in } \\
\text { meat science } \\
\text { integration }\end{array}$ & & $\Omega$ & & & \\
\hline $\begin{array}{l}\text { There is a lack } \\
\text { of parent and } \\
\text { community } \\
\text { support for } \\
\text { meat science } \\
\text { integration }\end{array}$ & & & & & \\
\hline $\begin{array}{l}\text { I have tried } \\
\text { integrating } \\
\text { meat science } \\
\text { and it was } \\
\text { unsuccessful }\end{array}$ & & & & & \\
\hline $\begin{array}{l}\text { There is a lack } \\
\text { of support from } \\
\text { local science } \\
\text { teacher(s) }\end{array}$ & & & & & \\
\hline $\begin{array}{l}\text { I have concerns } \\
\text { about discipline }\end{array}$ & $\bigcirc$ & & & 0 & \\
\hline
\end{tabular}




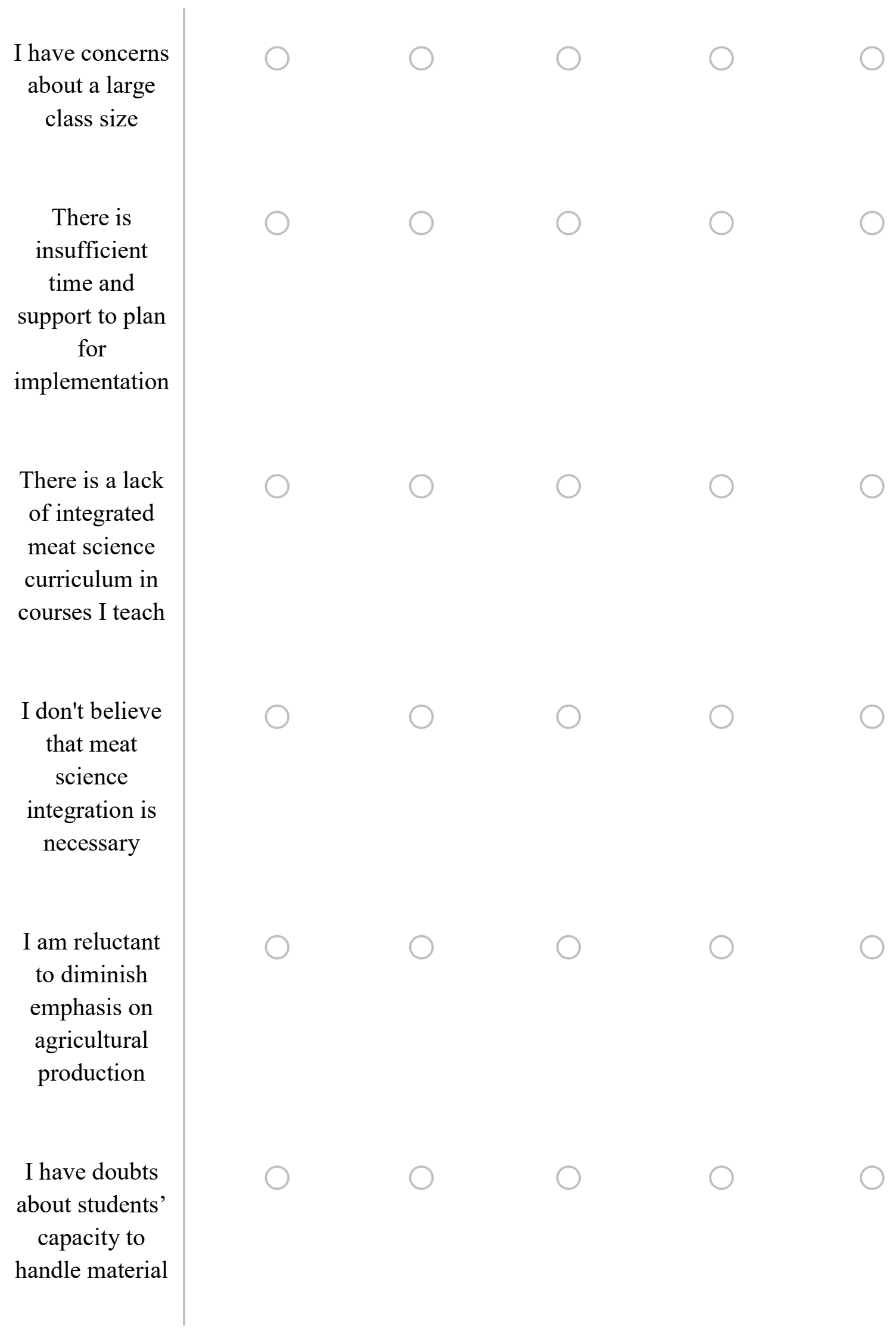




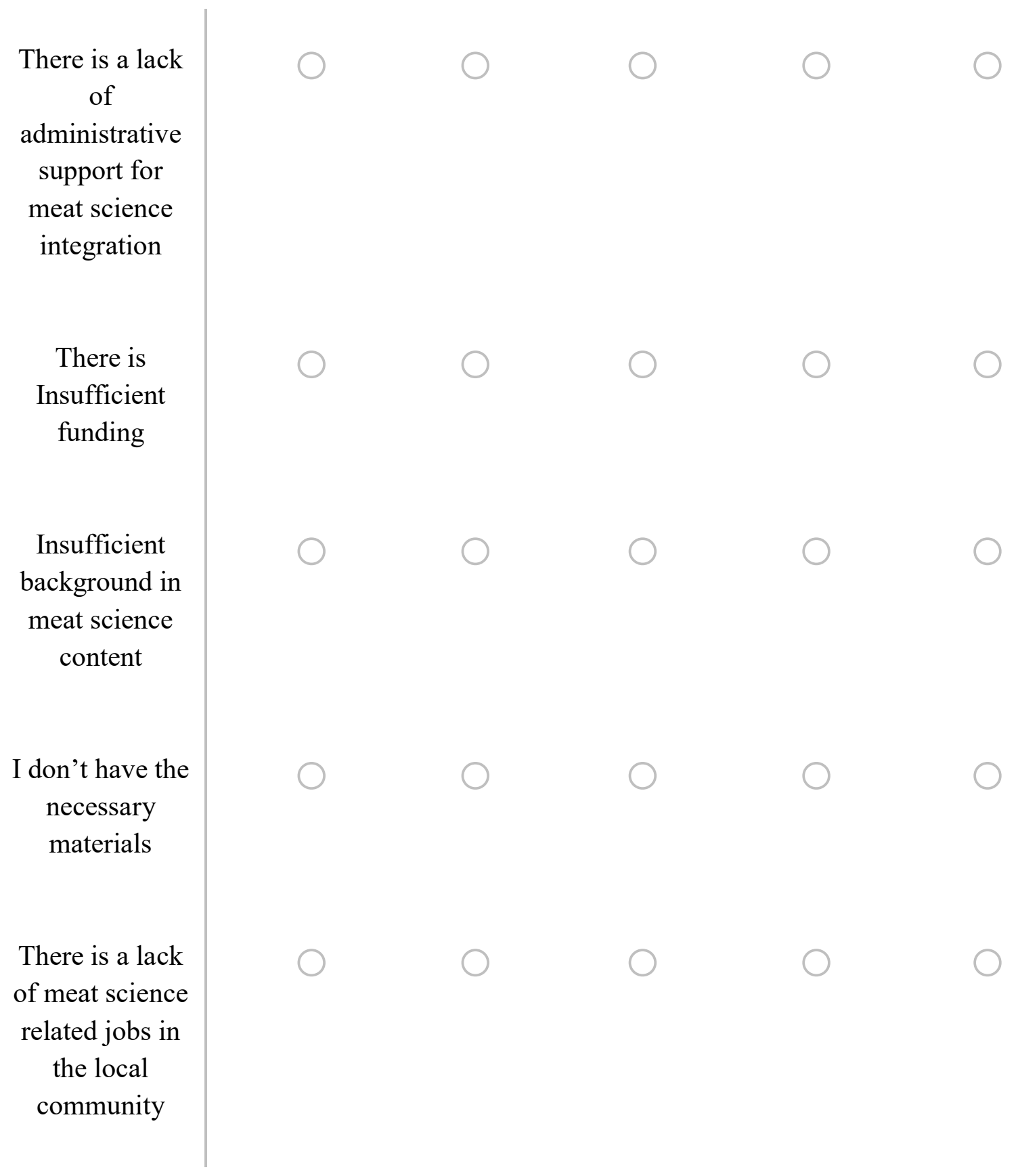

\section{Professional Development}

Q25 Please select any type of professional development that would help you to be more confident when teaching Meat Science (Select all that apply). 
STEM Professional Development

Meat Science Professional Development

Incorporating STEM components into meat science

Other (Please Specify)

\section{Demographics}

Q5 What was your age as of January 1st, 2021? (Please round up to the nearest number)

Q6 Please select which gender you identify as

Gender Neutral

Non-binary

Male

Female

Prefer not to say

Other (please specify) 
Q7 Including the $2020 \& 2021$ school year, How many years have you been teaching Agricultural Education?

Q8 Please indicate which description best matches the place you consider your school community.

My school community has more than 1,000 people per square mile, with a population of more than 50,000 people in the area.

My school community has less then 2,500 people in the area and encompasses a large area of land.

My school community has at least 2,500 people the area and has less than 500 people per square miles

Q56 What grade levels do you teach (please check all that apply)? 
Q57 Meat Science Training experience - Please check all that apply

I attended a formal college class focused on meat science and processing

I attended secondary classes which focused on meat science and processing

I have attended formal professional development on meat science and processing 